\title{
Evaluating the Performance of Factor Pricing Models for Different Stock Market Trends: Evidence from China
}

\author{
Haicheng $\mathrm{Shu}^{a}$ and $\mathrm{Yu} \mathrm{Wang}^{b}{ }^{\dagger *}$
}

October 6, 2019

\begin{abstract}
${ }^{a}$ Southwestern University of Finance and Economics, Email: haicheng.shu@swufe.edu.cn, Tel: $+862887092197$

${ }^{b}$ Department of Finance, School of Economics, and Wang Yanan Institute for Studies in Economics (WISE), Xiamen University, Xiamen, 361005 China, Email: yuwang@xmu.edu.cn, Tel: $+865922182129$
\end{abstract}

\begin{abstract}
This paper examines the performance of three nested factor pricing models for different market trends, such as bull, bear or consolidation, in China's stock market. Specifically, the models we consider are the Capital Asset Pricing Model (CAPM), the Fama-French threefactor model and the Fama-French extended five-factor model. Empirical results show that these models can explain the time-series variations in excess returns on a range of portfolios in the bear markets reasonably well, but have more difficulty explaining the cross-sectional variations in returns across the portfolios. We further adopt instability tests based on Hansen's statistics and recursive regressions, from which we derive the following two findings. First, we find the models to be more unstable in the bear and bull markets (trending markets) under time-series regression. Although the models in the time-series regressions usually perform well, this is due to the higher stock price synchronicity in trending markets, especially when it is bearish. Second, because the cross-sectional analysis of the Fama-MacBeth approach requires factor loadings to be estimated first by time-series regressions, the models inherit greater instability from trending markets. This causes the unitary parameter estimates to be less reliable, which in turn brings about difficulties in explaining the cross-sectional portfolio returns in trending markets.
\end{abstract}

Keywords: Asset pricing; Factor models; Market trends; Chinese stock market JEL classification: C52, C58, G12

\footnotetext{
$* \dagger$ Corresponding author.

Authors are deeply grateful to Peter Smith, Zaifu Yang, Yongcheol Shin, and Chris Florakis for many insightful comments and constructive suggestions. The authors also thank participants in the 2018 International Conference on Economic Theory and Applications, the 2019 Asia Meeting of the Econometric Society and the 2019 China Annual Conference of the Chinese Economists Society for helpful comments. All errors are our own.

This research is supported by the Fundamental Research Funds for the Central Universities (JBK190951) and (20720181038). Wang also acknowledges the financial support from the Departmental Ph.D. Studentship (Department of Economics and Related Studies, University of York), and the State Scholarship Fund (China Scholarship Council).
} 


\section{Introduction}

This paper examines the performance of factor models for different market trends, i.e., bull, bear and consolidation, in the Chinese stock market. We choose the Chinese stock market because it experienced two rounds of drastic booms and crashes in our sample, which did not occur in other markets. The models considered here are three nested models, including the Capital Asset Pricing Model, the Fama-French three-factor model and the Fama-French extended five-factor model. The empirical exercise divides the full sample for further comparison into six sub-periods based on whether the market is bull, bear or consolidation.

The contributions of this paper are as follows. We find that the selected models tend to explain the time-series variations in portfolio returns better in the bear markets. However, these models have greater difficulty explaining the cross-sectional variations in returns during crashes according to the Fama-MacBeth (1973) approach. We try to provide possible interpretations for these ostensibly conflicting findings by examining the models' instability using Hansen's (1992) instability test and graphing the changes in the models' parameters estimated from recursive timeseries regressions. Empirical evidence shows that the models' parameter estimates (i.e., factor loadings or exposures) are highly unstable when the market crashes; nevertheless, the reasonably good performance of these models in time-series regressions should be the result of higher stock price synchronicity in the trending markets of bull and bear. In the meantime, we further argue that the greater instability implicitly indwelling in models' unitary parameter estimates from the firststage time-series regressions of the Fama-MacBeth (1973) approach during the trending markets should be the cause of the ostensibly contradictory findings.

The empirical studies on factor pricing models evaluate their explanatory power for returns on financial assets. That is, can the factors of a pricing model help to reduce pricing errors and explain more of the variations in asset returns? Many factor pricing models were developed as a response to the empirical failures of the Capital Asset Pricing Model (hereafter CAPM) of Sharpe (1964) and Lintner (1965a,b) and the Consumption CAPM (hereafter CCAPM) of Lucas (1978) and Breeden (1979). Nevertheless, the CAPM and CCAPM are still attractive because they explicitly specify the relevant measure of risk and the relation between expected returns and risk. In this sense, the CAPM and CCAPM can guide model selection in empirical applications.

In contrast, most factor pricing models are motivated by observed patterns (anomalies) in average returns. For example, the well-known Fama-French (1993) three-factor model is motivated by the size and book-to-market value (hereafter B/M) patterns in average returns. Over time, many patterns in average returns have been discovered and have become potential candidates for inclusion in factor models.

The problem, however, is that if they are not grounded in theory then factor models risk degenerating into long lists of factors that come close to spanning the ex-post mean-varianceefficient (MVE) tangency portfolio of a particular period. In other words, choosing factors for pricing models can potentially fall into the trap of data dredging or data mining exercises. For example, Harvey et al. (2015) catalogue 316 anomalies proposed as potential factors in assetpricing models. Given the plethora of factors that might be included in a model, choosing among competing models is an open challenge.

So, how can we avoid data dredging? Fama and French (2018) suggest that, given the model robustness in different periods and markets, model comparisons in any investigation should be limited by theory, even an umbrella theory like the dividend discount model. For example, Fama and French $(2015,2016)$ invoke the dividend discount model to motivate their five-factor model; while Hou et al. (2015) are inspired by investment-based asset pricing to introduce the investment 
and profitability factors as the pricing factors. In our tests of nested models, we limit comparisons to the three-factor model of Fama and French (1993) (hereafter FF3) versus the CAPM, and the five-factor extension in Fama and French (2015) (hereafter FF5) versus the FF3. The reason for these choices is because these models are considered to be among the most representative factor pricing models (Fama and French, 2018 and Kozak et al., 2018). Due to the absence of theoretical justification and the lack of data, we exclude the commonly-examined momentum factor of Carhart (1997) from the factor models. ${ }^{1}$ Thus, we limit both the total number of factors and the number of competing models.

A plenty of studies examine the performance of factor pricing models. Interesting phenomena have been found by comparing the models across different sample periods. One example is the reversal of factor effects, which indicates that the usual positive factor premiums could become negative in some periods. This reversal has widely been proved in the literature including Gompers and Metrick (1998), Dimson and Marsh (1998), Gustafson and Miller (1999), Faff (2004) and Pham (2007). Another example is volatility clustering, first noted by Mandelbrot (1963) that "large changes tend to be followed by large changes, of either sign; and small changes tend to be followed by small changes." This clustering was also documented by Granger and Ding (1995) and Ding and Granger (1996). Ding et al. (1993) and Barndorff-Nielsen and Shephard (2010) further found long-range dependence in volatility time series. Thus, the evidence in the literature suggests that the factor models do not necessarily perform similarly well within different sample periods.

In fact, the market conditions could change over time, causing the different performance of factor models. Nonetheless, the current comparisons of model performance usually do not explicitly consider the changing market conditions. Specifically, few studies divide the sample based on market trends. We argue that the change in market trends represents the change in market conditions. In the meantime, there does not seem to be a single reliable statistical inference measure to compare the performances of factor models across different periods. As such, the objective of this study is, by employing comprehensive methods, to provide insights into the performance of factor models under different market conditions represented by the market trends.

Besides of the methods mentioned in this study, in our preliminary analysis, we also employed the Markov-regime-switching (hereafter MRS) regression model to examine the three factor models. We found at least two different states (regimes) for the factor models. When the number of states is set to be three or more, however, the quasi-Newton optimisation is hard to converge for most of the 25 size and $\mathrm{B} / \mathrm{M}$ sorted portfolios. In fact, the convergence problem frequently arises when a model is set up with too many states. Moreover, we argued that the MRS model does not serve our goal well. This is because we intend to test the performance of factor models for different market trends, each of which is a perceived tendency of financial markets to move in a particular direction within a period. The states in the MRS model cannot be directly observed beforehand, however; and the time of transition from one state to another, and the duration between changes in the states, is random. Nevertheless, the MRS regression results reveal the fact that the performance of factor models varies significantly in different periods.

The remainder of this paper is structured as follows: Section 2 addresses data issues and provides summary statistics for the factors and portfolio returns. Section 3 examines the models by the time-series analysis. Section 4 conducts the cross-sectional analysis based on the FamaMacBeth approach. Section 5 re-examines the models based on instability tests and recursive regressions, and provides evidence to explain the ostensibly inconsistent findings discovered in Sections 3 and 4 . Section 6 concludes.

\footnotetext{
${ }^{1}$ Hou et al. (2015) also present an empirical justification for excluding the Carhart's momentum factor from their model.
} 


\section{Data}

In this section, we address data issues and provide summary statistics (Table 1,2 and 3) for the factors and portfolio returns.

\subsection{Data issues and sample period}

We obtained data from two commercially accessible databases. Specifically, we acquired data from the RESSET database for the 25 size and $\mathrm{B} / \mathrm{M}$ sorted portfolio excess returns, in addition to the market, size and value factors ${ }^{2}$. The CSMAR database ${ }^{3}$, meanwhile, provides data on the profitability and investment factors up to November 30, 2016. We selected the data series covering the A-share stocks listed in the Shanghai and Shenzhen Main Board, the Shenzhen Small and Medium Enterprise (SME) Board, and the Shenzhen Growth Enterprise Market (GEM). Weights of stocks in each portforlio are based on free float values. The data frequency is daily because a trend, boom or crash, in our sample lasts for less than one year, and we can only have enough observations with daily returns.

Our sample begins on December 1, 2006 for two reasons. First, in 2005, the Chinese government introduced the Split Share Structure Reform. We left about one year for the market to react to this policy change. Second, we include the daily data in December 2006 into our sample in order to make the first bull market a generally complete one. It is widely recognised that the first boom started from December 2006. Our sample ends on November 30, 2016 due to the unavailability of data for the profitability and investment factors after that date.

Figure 1 draws the time-series changes in China's two market indexes - the Shanghai Composite Index (ShIDX) and the Shenzhen Component Index (SzIDX), during the period from December 1, 2006 to November 30, 2016. This period witnessed two rounds of historical booms and crashes in the Chinese stock market. The first historical peak of China's stock market occurred in October 2007, with the highest point of the ShIDX at 6092.06 on October 16, 2007 and the highest point of the SzIDX at 19531.16 on October 31, 2007. After that, the Chinese stock market crashed. On November 4, 2008, the two indexes dropped dramatically and reached their trough at 1706.7 and 5668.81 , respectively. After a long run of consolidation, China's stock market soared again from the first quarter of 2014, reaching the second historical peak on June 12, 2015, with the ShIDX peaking at 5166.35 and the SzIDX at 18098.27. Then, it crashed again and dropped to the trough on Jan 28, 2016, with the ShIDX at 2655.66 and the SzIDX at 9082.59. These dramatic turns in China's stock market make it appealing to examine the performance of factor pricing models in different market trends.

Thus, our sample is further divided into six sub-periods to represent different trends of markets. Sub-period 1 (Bull): December 1, 2006 to October 31, 2007; Sub-period 2 (Bear): November 1, 2007 to November 4, 2008; Sub-period 3 (Consolidation):from November 5, 2008 to March 20, 2014; Sub-period 4 (Bull): March 21, 2014 to June 12, 2015; Sub-period 5 (Bear): June 13, 2015 to January 28, 2016; and Sub-period 6 (Consolidation): January 29, 2016 to November 30, 2016. The six sub-periods are separated by five red vertical lines in Figure 1.

\subsection{The factors}

The factors on the right-hand side (RHS) of the model equations are the Fama-French five factors: market, size, value, profitability, and investment. Table 1 shows the summary statistics for the

\footnotetext{
${ }^{2}$ http://db.resset.com

${ }^{3}$ http://cn.gtadata.com/Home
} 


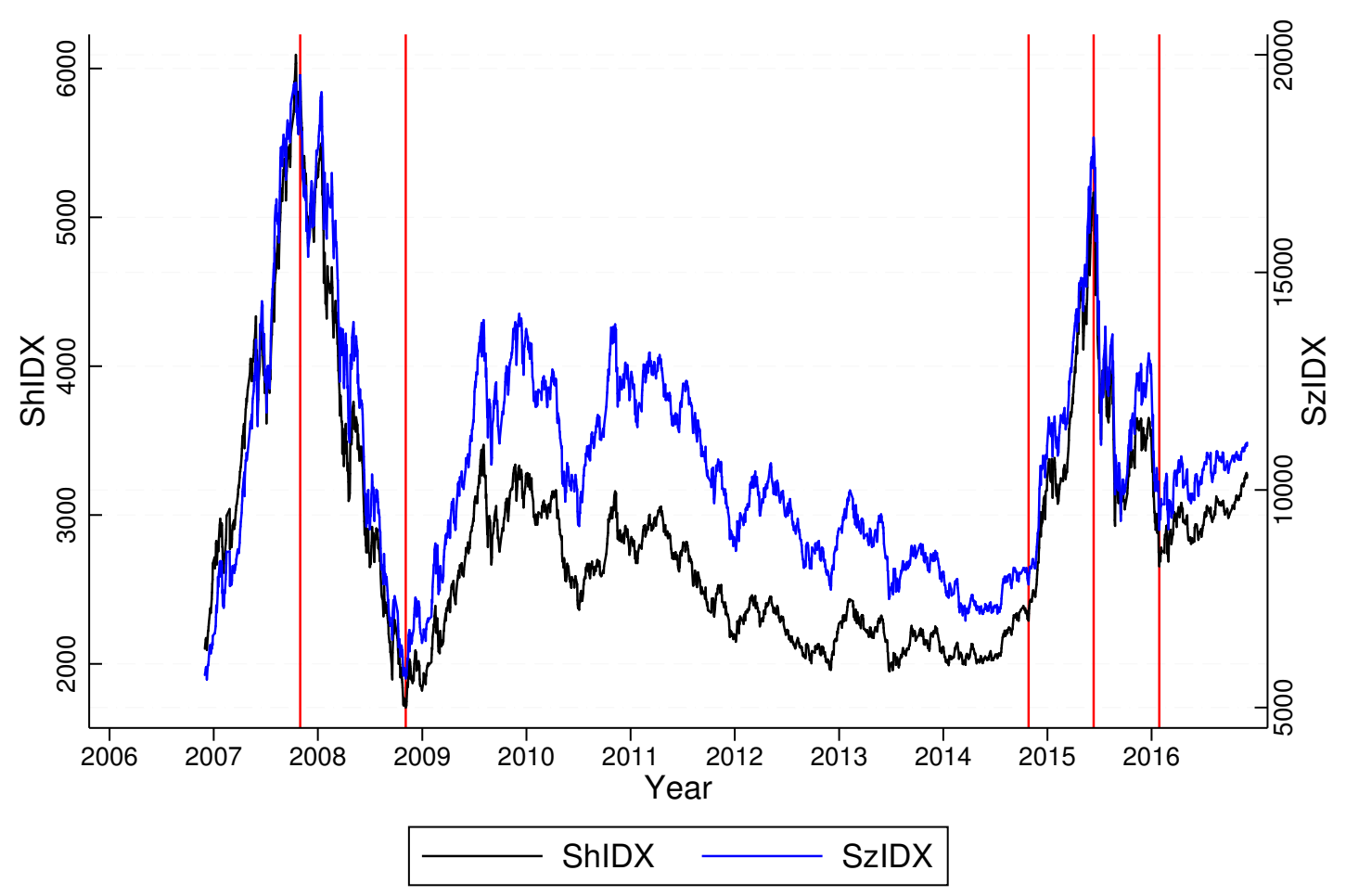

Figure 1: Changes in China's stock market indexes

Note: Sample period is December 1, 2006 to November 30, 2016. The ShIDX is plotted against the left y-axis and the SzIDX against the right y-axis. The red lines separate the full period into six sub-periods to represent different trends of China's stock market.

Data Source: CSMAR

five factors over the full sample period. The top panel presents the descriptive statistics for the five factors, while the bottom panel shows the correlation between the variables. The daily excess return on the market portfolio (MKT) is positive but insignificant. This positive market premium is attributed to the fact that the market matures over the long run, although it periodically booms and crashes. The insignificance of the market premium is not surprising if we notice that the Chinese stock market experienced two rounds of boom-crash during our sample period, returning close to its initial level. The insignificantly positive market factor premium is also found in other studies, e.g., Chen et al. (2015), on the Chinese market. The market premium might not be always positive, however. As we will see, it could be negative, even significantly, in some sub-periods.

The size premium (SMB) is positive and highly significant, while the value premium (HML) is negative and insignificant. Thus, we find a strong and positive size effect but a weak and negative value premium. This finding comports with Wang and Xu (2004) and Chen et al. (2015), but contravenes Chen et al. (2010), Cakici et al. (2015) and Carpenter et al. (2015), where both strong size and value effects are found. The different findings of the significance of the value premium in the Chinese market might stem from the different choices of sample periods. Different sample periods can lead to different magnitudes and significance of factor premium. Chen et al. (2015) also document that the market, size and value factors are insignificant in the US during the period from July 1997 to December 2013. Even the signs of factor premiums can change in different periods, which has been found in the US, UK, Australia, and Japan by Gompers and Metrick (1998), Dimson and Marsh (1998), Gustafson and Miller (1999), Faff (2004) and Pham (2007). This suggests that even if we find a weak factor premium in our sample, we cannot just drop it from the pricing model, especially when we find the generally significant factor betas in time-series 
Table 1: Summary statistics for five factors

\begin{tabular}{|c|c|c|c|c|c|}
\hline & MKT & SMB & HML & RMW & CMA \\
\hline \multicolumn{6}{|c|}{ Panel A: Descriptive statistics } \\
\hline Obs. & 2431 & 2431 & 2431 & 2431 & 2431 \\
\hline Mean & 0.058 & $0.076^{* * *}$ & -0.011 & $-0.025^{* *}$ & 0.013 \\
\hline$t$ & 1.451 & 4.697 & -0.868 & -1.996 & 1.408 \\
\hline Med & 0.140 & 0.150 & -0.040 & -0.064 & 0.019 \\
\hline Std. Dev. & 1.983 & 0.795 & 0.617 & 0.612 & 0.472 \\
\hline Min & -9.440 & -6.360 & -3.780 & -2.961 & -3.214 \\
\hline Max & 9.920 & 4.280 & 4.370 & 5.280 & 2.096 \\
\hline Skewness & -0.572 & -1.039 & 0.354 & 1.096 & -0.410 \\
\hline Kurtosis & 6.352 & 8.157 & 6.972 & 10.592 & 6.327 \\
\hline \multicolumn{6}{|c|}{ Panel B: Correlation } \\
\hline MKT & 1 & & & & \\
\hline SMB & $0.186^{* * *}$ & 1 & & & \\
\hline HML & $0.048^{* *}$ & $-0.452^{* * *}$ & 1 & & \\
\hline RMW & $-0.189 * * *$ & $-0.786^{* * *}$ & $0.320^{* * *}$ & 1 & \\
\hline CMA & $-0.042^{* *}$ & $0.446^{* * *}$ & -0.004 & $-0.576^{* * *}$ & 1 \\
\hline
\end{tabular}

$* * * \mathrm{p}<0.01,{ }^{* *} \mathrm{p}<0.05,{ }^{*} \mathrm{p}<0.1$.

The full sample period is Dec 1, 2006, to Nov 30, 2016, with 2431 trading days. Returns are daily and in percent. Data Source: MKT, SMB, HML are from RESSET, while RMW and CMA are from CSMAR.

regression. The value factor is still an important factor in pricing assets unless we can find other factor(s) that can fully take over the role of it and better explain equity returns. ${ }^{4}$

As for the pair of newly proposed factors, the profitability premium is significantly negative, while the investment premium is positive but insignificant. These findings contravene other studies. For example, Guo et al. (2017) find a strong monthly profitability premium and a weak and negative investment premium from July 1995 to June 2015, and weak profitability and investment premiums during July 1994 to December 2016 are reported in Huang (2018).

Panel B reports the correlations between the factors. The correlations of the market factors with the other four factors are relatively small, and our entire sample finds positive correlations of the market factor with the size and value factors, but negative with the profitability and investment factors. Aside from the market factor, the correlations between the other four factors are generally high, except for the pair of the value and investment factors. Among those factors, the correlation between the size and value factors is -0.452 . The profitability factor is negatively correlated with the size and investment factors, and the corresponding correlations are -0.786 and -0.576 , respectively. The lowest correlation of -0.004 is found between the value and investment factors.

Figure 2 plots the time-series changes in the premiums on the five factors over the full period. The sub-periods, separated by the red vertical lines, represent the different market trends. We see that the factor premiums generally present higher volatility in the periods of trending markets than in consolidations. Compared between the two types of trending markets, the volatility seems to be even higher in the crashes than in the booms. It is not surprising that the market factor tends to present more downside volatility in market crashes, and more upside volatility with booms. Volatility clustering is also clearly presented in this figure. The volatility appears more significant in the trending markets, and the range of changes in factor premiums narrows down gradually in the consolidations.

Due to this significant difference in the factors' behaviour in the different market trends, we

\footnotetext{
${ }^{4}$ Fama and French $(2015,2016)$ and Hou et al. (2015) suggest that the two new profitability and investment factors could challenge the role of the value factor, but the evidence in the current literature is not strong enough to exclude the value factor from the models. In fact, studies examining the Fama-French five-factor model are just in their infancy, and the evidence is still relatively limited compared to that for the Fama-French three-factor model.
} 


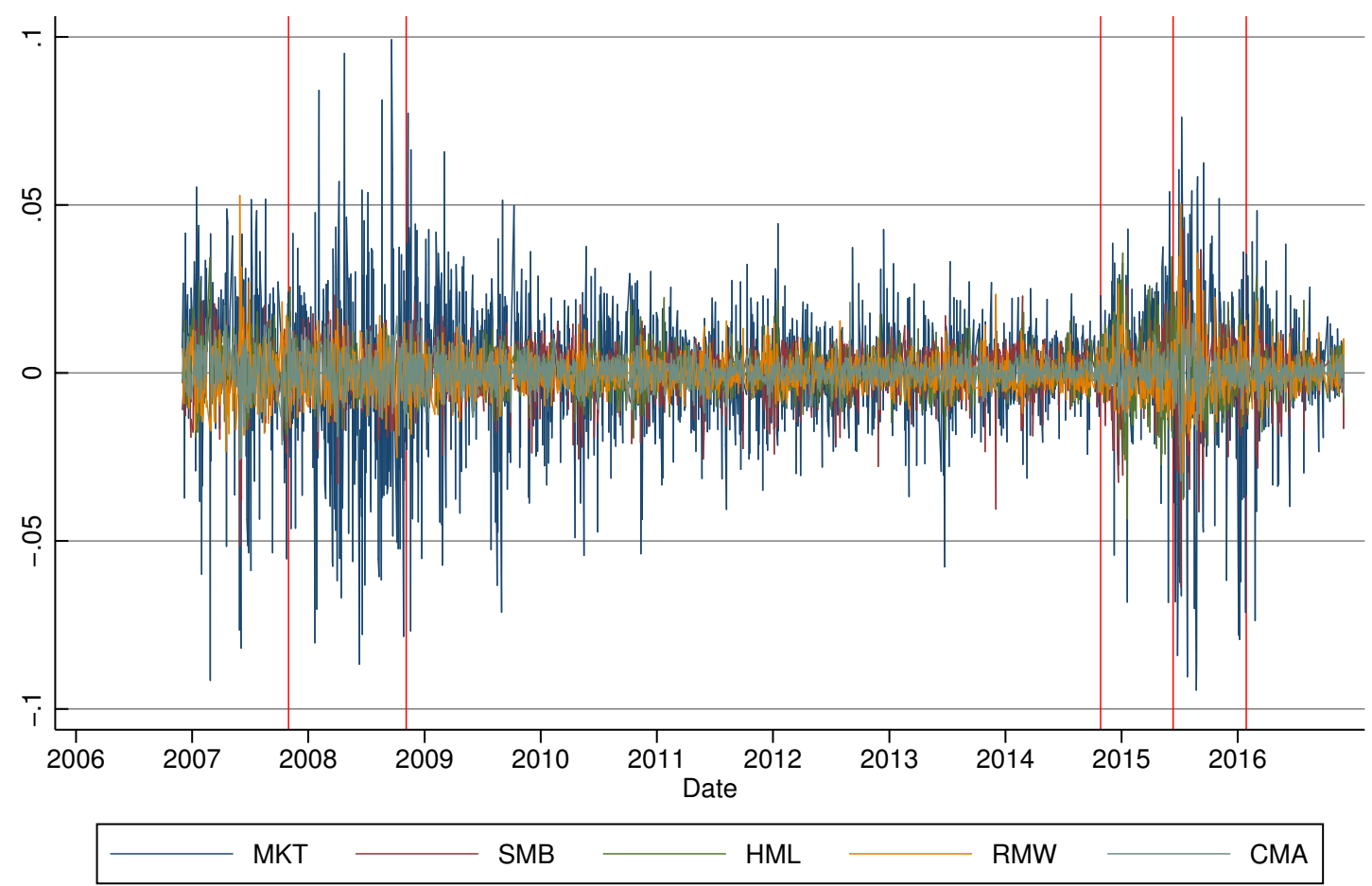

Figure 2: Time-series change in the premiums on pricing factors

Note: This figure plots the time-series changes in the premiums on the five pricing factors. The red lines separate the full period into six sub-periods to represent different trends of China's stock market.

also provide the sub-sample descriptive statistics for the five factors in Table 2. This table confirms the time-series patterns of the factors. The market factor premium is significantly positive in the two sub-periods of the bull market. It is significantly negative in the first bear period, and negative but close to being significant at the $10 \%$ significance level in the second bear period. In the two consolidation periods, the market premium is positive but insignificant and the size premium is significantly positive, while generally insignificant in other sub-periods, except in the first bear market. The value premium is generally insignificant, except for the first consolidation when it is marginally significant but negative. The profitability premium is significantly negative in the first consolidation and the second boom. The investment premium is generally positive but insignificant in all sub-periods.

The standard deviations of all factor premiums are higher when the market is bullish and bearish, compared with when the market consolidates. In the first round of boom-crash, the standard deviation of the market and investment factors are higher in the crash, while the size, value and profitability factors have a higher standard deviation in the boom. In the second round of boom-crash, the market, size, profitability, and investment factors are more volatile in the crash, but not so for the value factor. In all sub-periods, the market factor presents the highest volatility among the five factors.

The different levels of significance and the magnitudes of the factor premiums suggest that the behaviour of risk premiums are not necessarily consistent over time, and they should be related to, or might be driven by, different market conditions. Our findings hint to fund managers that adhering to a risk factor-based strategy cannot guarantee a successful investment. Thus, they should adjust the investment position according to the changes in market trends.

Because our sample is divided based on the market trends represented by the two market 
Table 2: Sub-sample summary statistics for the five factors

\begin{tabular}{|c|c|c|c|c|c|c|c|c|c|c|}
\hline & MKT & SMB & HML & RMW & CMA & MKT & SMB & HML & RMW & CMA \\
\hline & \multicolumn{5}{|c|}{ Panel A: Sub-period 1 (Bull) } & \multicolumn{5}{|c|}{ Panel B: Sub-period 2 (Bear) } \\
\hline & \multicolumn{5}{|c|}{ Dec 1, 2006 to Oct 31, 2007, T=221 } & \multicolumn{5}{|c|}{ Nov 1, 2007 to Nov 4, 2008, T=247 } \\
\hline Mean & $0.559^{* * *}$ & -0.013 & 0.016 & -0.008 & 0.033 & $-0.461 * * *$ & $0.099^{*}$ & 0.036 & -0.009 & 0.025 \\
\hline$t$-stat & 3.437 & -0.193 & 0.301 & -0.122 & 0.695 & -2.383 & 1.823 & 1.055 & -0.205 & 0.595 \\
\hline Std. Dev. & 2.417 & 0.974 & 0.772 & 0.956 & 0.699 & 3.039 & 0.849 & 0.538 & 0.671 & 0.670 \\
\hline Med & 1.000 & 0.030 & 0.040 & -0.075 & 0.039 & -0.490 & 0.200 & 0.030 & -0.030 & 0.078 \\
\hline Min & -9.150 & -5.150 & -2.200 & -2.338 & -2.583 & -8.670 & -3.290 & -1.960 & -2.514 & -1.890 \\
\hline \multirow[t]{3}{*}{ Max } & 5.530 & 2.170 & 3.080 & 5.280 & 2.016 & 9.920 & 2.310 & 1.430 & 1.909 & 1.691 \\
\hline & \multicolumn{5}{|c|}{ Panel C: Sub-period 3 (Consolidation) } & \multicolumn{5}{|c|}{ Panel D: Sub-period \& (Bull) } \\
\hline & \multicolumn{5}{|c|}{ Nov 5, 2008 to Oct 27, 2014, T=1450 } & \multicolumn{5}{|c|}{ Oct 28, 2014 to Jun 12, 2015, $T=155$} \\
\hline Mean & 0.054 & $0.078^{* * *}$ & $-0.021^{*}$ & $-0.034^{* * *}$ & 0.013 & $0.582^{* * *}$ & 0.106 & -0.016 & $-0.101^{*}$ & 0.031 \\
\hline$t$-stat & 1.384 & 4.704 & -1.739 & -3.071 & 1.303 & 4.041 & 1.278 & -0.187 & -1.877 & 0.880 \\
\hline Std. Dev. & 1.491 & 0.633 & 0.464 & 0.424 & 0.369 & 1.794 & 1.028 & 1.076 & 0.670 & 0.443 \\
\hline Med & 0.090 & 0.145 & -0.050 & -0.059 & 0.015 & 0.630 & 0.260 & -0.090 & -0.106 & -0.014 \\
\hline Min & -7.680 & -4.050 & -1.870 & -1.815 & -1.463 & -6.830 & -3.250 & -3.390 & -1.312 & -1.442 \\
\hline \multirow[t]{3}{*}{$\operatorname{Max}$} & 7.730 & 2.290 & 2.140 & 2.341 & 2.096 & 5.390 & 2.600 & 2.760 & 2.645 & 1.589 \\
\hline & \multicolumn{5}{|c|}{ Panel E: Sub-period 5 (Bear) } & \multirow{2}{*}{\multicolumn{5}{|c|}{$\begin{array}{l}\text { Panel F: Sub-period 6 (Consolidation) } \\
\text { Jan 29, 2016 to Nov 30, 2016, T=203 }\end{array}$}} \\
\hline & & $13,2015 t$ & Jan 28, & $016, T=15$ & & & & & & \\
\hline Mean & -0.405 & 0.089 & -0.049 & 0.090 & -0.041 & 0.129 & $0.094^{* *}$ & 0.010 & -0.024 & 0.012 \\
\hline$t$-stat & -1.512 & 0.755 & -0.583 & 0.931 & -0.717 & 1.352 & 2.239 & 0.252 & -0.740 & 0.584 \\
\hline Std. Dev. & 3.333 & 1.468 & 1.045 & 1.197 & 0.711 & 1.360 & 0.599 & 0.559 & 0.464 & 0.294 \\
\hline Med & 0.220 & 0.340 & -0.190 & -0.144 & 0.050 & 0.100 & 0.170 & -0.030 & -0.066 & 0.035 \\
\hline Min & -9.440 & -6.360 & -3.780 & -2.961 & -3.214 & -7.370 & -2.830 & -1.420 & -1.353 & -1.130 \\
\hline $\operatorname{Max}$ & 7.610 & 4.280 & 4.370 & 5.038 & 1.772 & 4.830 & 1.410 & 2.600 & 2.120 & 0.998 \\
\hline
\end{tabular}

This table reports the summary statistics for the five factors within six sub-periods separated based on market trends. Returns are daily and in percent.

Data Source: MKT, SMB, HML are from RESSET, while RMW and CMA are from CSMAR.

indexes, the behaviour of the market premium also comports with market trends: negative when the market is in the crash, and positive when in the boom. It is also positive (although insignificant) in the consolidation, because the market increased slowly within our two consolidation sub-samples.

\subsection{5 size-B/M sorted portfolio excess returns}

In our study, the dependent variables on the left-hand side (LHS) of the model equations are the 25 size-B/M sorted portfolio excess returns over the risk-free rate. As stated by Petkova (2006), these size-B/M sorted portfolios are among the most challenging sets of assets for existing asset pricing models. The descriptive statistics for these portfolio excess returns are reported in Table 3. Over our sample period, the average excess returns on the 25 portfolios are all positive. The panels of mean, median, and $t$-statistic indicate that the small and growth (low $\mathrm{B} / \mathrm{M}$ ratio) portfolios tend to be awarded higher and more significant excess returns, compared with the big and value (high B/M ratio) portfolios. Meanwhile, these higher premiums present higher volatility, as shown by the higher standard deviations. Due to the imposed daily price limits of 10 percent on regular stocks ${ }^{5}$ in the Chinese stock market, it is not surprising that the minimum and maximum average returns are both bounded at around $\pm 10 \%$.

\footnotetext{
${ }^{5}$ The term of "regular stocks" here is opposite to the term of "ST stocks" in the Chinese stock market. The latter refers to stocks of companies with "special treatments (ST)". This is where a company has reported repeated losses and is therefore deemed to be at risk. In such cases the letters "ST" are added by the stock exchanges in front of the company abbreviation. As well as potentially being delisted, such stocks are subject to a tighter daily price variation restriction $( \pm 5 \%)$ than the 10 percent for regular shares.
} 
Table 3: Descriptive statistics for 25 size-B/M sorted portfolio excess returns

\begin{tabular}{|c|c|c|c|c|c|c|c|c|c|c|}
\hline \multirow{2}{*}{$\begin{array}{c}\text { Size } \\
\text { quintile }\end{array}$} & \multicolumn{10}{|c|}{$\mathrm{B} / \mathrm{M}$ quintile } \\
\hline & Low & 2 & 3 & 4 & High & Low & 2 & 3 & 4 & High \\
\hline & \multicolumn{5}{|c|}{ Mean } & \multicolumn{5}{|c|}{$t$} \\
\hline Small & 0.164 & 0.171 & 0.174 & 0.160 & 0.143 & 3.453 & 3.411 & 3.455 & 3.163 & 2.881 \\
\hline 2 & 0.118 & 0.134 & 0.142 & 0.130 & 0.109 & 2.417 & 2.721 & 2.786 & 2.574 & 2.213 \\
\hline 3 & 0.104 & 0.108 & 0.114 & 0.114 & 0.089 & 2.158 & 2.167 & 2.302 & 2.293 & 1.842 \\
\hline 4 & 0.077 & 0.082 & 0.094 & 0.075 & 0.065 & 1.635 & 1.662 & 1.886 & 1.547 & 1.367 \\
\hline \multirow[t]{2}{*}{ Big } & 0.050 & 0.048 & 0.045 & 0.064 & 0.032 & 1.182 & 1.078 & 0.998 & 1.451 & 0.768 \\
\hline & \multicolumn{5}{|c|}{ Std Dev } & \multicolumn{5}{|c|}{ Median } \\
\hline Small & 2.348 & 2.472 & 2.479 & 2.490 & 2.455 & 0.454 & 0.463 & 0.435 & 0.425 & 0.428 \\
\hline 2 & 2.404 & 2.437 & 2.505 & 2.488 & 2.420 & 0.352 & 0.375 & 0.384 & 0.375 & 0.318 \\
\hline 3 & 2.384 & 2.466 & 2.443 & 2.445 & 2.389 & 0.354 & 0.345 & 0.349 & 0.317 & 0.280 \\
\hline 4 & 2.336 & 2.423 & 2.446 & 2.400 & 2.359 & 0.259 & 0.292 & 0.315 & 0.275 & 0.208 \\
\hline \multirow[t]{2}{*}{ Big } & 2.092 & 2.174 & 2.217 & 2.184 & 2.067 & 0.142 & 0.162 & 0.119 & 0.095 & 0.074 \\
\hline & \multicolumn{5}{|c|}{ Min } & \multicolumn{5}{|c|}{ Max } \\
\hline Small & -9.569 & -9.679 & -9.559 & -9.839 & -9.678 & 9.391 & 9.698 & 9.948 & 9.951 & 10.008 \\
\hline 2 & -9.619 & -9.889 & -9.999 & -9.999 & -9.779 & 9.408 & 9.851 & 10.018 & 9.891 & 10.021 \\
\hline 3 & -9.999 & -9.999 & -9.999 & -9.899 & -9.849 & 10.001 & 9.991 & 10.008 & 10.001 & 9.998 \\
\hline 4 & -9.909 & -9.969 & -9.989 & -9.959 & -9.949 & 9.988 & 9.991 & 10.011 & 9.988 & 10.008 \\
\hline Big & -9.889 & -9.899 & -9.658 & -9.779 & -9.629 & 9.991 & 9.998 & 9.988 & 9.998 & 9.948 \\
\hline
\end{tabular}

\section{Time-series Analysis}

In this section, we conduct the conventional time-series analysis. Specifically, we first run the timeseries regressions of the 25 portfolio returns on the factors, then conduct the GRS test (Gibbons et al., 1989) and report results for selected performance measures, followed by discussions on these measures. The time-series regressions focus on the three nested factor pricing models, i.e., the CAPM, the FF3 which includes the additional size and value factors, and the FF5 to which the other profitability and investment factors are added.

\subsection{Time-series regression}

To illustrate the time-series regression, we take the FF5 as an example underneath, while the FF3 and the CAPM are nested within the FF5. The FF5 includes a market factor, a size factor, a value factor, a profitability factor, and an investment factor:

$$
R_{i t}-R_{f t}=\alpha_{i}+\beta_{M, i} M K T_{t}+\beta_{S, i} S M B_{t}+\beta_{H, i} H M L_{t}+\beta_{R, i} R M W_{t}+\beta_{C, i} C M A_{t}+e_{i t}
$$

In Equation (1), $R_{i t}$ is the day $t$ return on portfolio $i . R_{f t}$ is the risk-free rate observed at the beginning of day $t$. Thus, the LHS variable is the excess return on portfolio $i$ on day $t . M K T_{t}$ is the market factor or the excess return on market portfolio over the risk-free rate on day $t$. Similarly, $S M B_{t}, H M L_{t}, R M W_{t}$, and $C M A_{t}$ are the size, value, profitability and investment factors on day $t$, respectively. The other two models are nested within the FF5, i.e., the CAPM includes only $M K T$, and the FF3 includes $M K T, S M B$, and $H M L$.

In order to save space, we do not report the detailed regression results for all 25 portfolios. Instead, we summarise these results in Table 4. For each model, we report the mean, standard deviation, median, minimum and maximum values for each estimated coefficient (i.e., factor loading or exposure) and adjusted $R^{2}$ across the 25 regressions. The intercept, $\alpha$, is in percent. In addition, the row " $0 \sim 1 \%$ " reports the number of significant corresponding coefficients at the $1 \%$ level, and 
Table 4: Summary of time-series regression results

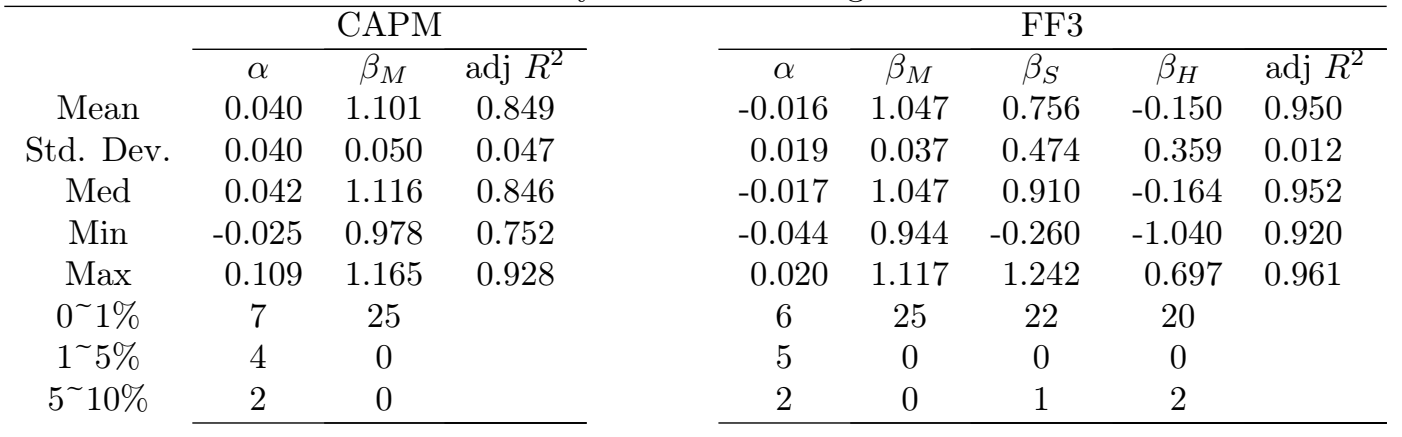

\begin{tabular}{cccccccc} 
& \multicolumn{7}{c}{ FF5 } \\
\cline { 2 - 7 } Mean & \multicolumn{1}{c}{$\alpha$} & $\beta_{M}$ & $\beta_{S}$ & \multicolumn{1}{c}{$\beta_{H}$} & $\beta_{R}$ & $\beta_{C}$ & $\operatorname{adj} R^{2}$ \\
\cline { 2 - 7 } Std. Dev. & 0.012 & 1.057 & 0.631 & -0.208 & -0.049 & 0.266 & 0.953 \\
Med & -0.017 & 0.037 & 0.474 & 0.352 & 0.065 & 0.104 & 0.010 \\
Min & -0.039 & 0.964 & -0.289 & -1.059 & -0.155 & 0.081 & 0.928 \\
Max & 0.026 & 1.127 & 1.175 & 0.644 & 0.109 & 0.528 & 0.964 \\
$0 \sim 1 \%$ & 5 & 25 & 24 & 22 & 3 & 23 & \\
$1 \sim 5 \%$ & 4 & 0 & 1 & 0 & 4 & 2 & \\
$5 \sim 10 \%$ & 6 & 0 & 0 & 1 & 3 & 0 &
\end{tabular}

This table summarises the results of the 25 time-series regressions. For each model, we report the mean, standard deviation, median, minimum and maximum values for each coefficient (i.e., factor loading or exposure) and adjusted $R^{2}$ across the 25 regressions. The intercept, $\alpha$, is in percent. The rows of " $0 \sim 1 \%$ ", " $1 \sim 5 \%$ " and " $5 \sim 10 \%$ " report the numbers of significant corresponding coefficients at the $1 \%$ level, between the $1 \%$ and $5 \%$ levels and between the $5 \%$ and $10 \%$ levels, respectively.

the row " $1 \sim 5 \%$ " presents the number of significant corresponding coefficients between the $1 \%$ and $5 \%$ levels. Similarly, the row " $5 \sim 10 \%$ " shows the number of significant coefficients between the $5 \%$ and $10 \%$ levels. The corresponding standard errors are the Newey-West (1987) standard errors, robust to heteroskedasticity (White, 1980) and autocorrelation (HAC). ${ }^{6}$

The intercept of a factor pricing model represents the pricing error. The closer to zero the intercept, the less pricing error the model produces, and thus, the better the model performs. From this table, we can see that over the full sample, the FF5 produces less significant intercepts than the CAPM and the FF3. The average intercept of the FF5 is closer to zero, and the standard deviation of the intercepts is smaller for the FF5. Moreover, as we add more factors into the model, the mean, median, minimum and maximum of the adjusted $R^{2}$ increase, and its standard deviation decreases. Thus, over the full sample, the FF5 outperforms the other competing models in terms of the estimated intercepts and the adjusted $R^{2}$. This finding is consistent with the general conclusion in previous studies on factor models. As for the factor loadings, it is noticeable that the profitability factor (RMW) loading is very insignificant over the full sample. This might be because the profitability factor is highly correlated with other factors, as shown in Panel B of Table 1. The other factor loading estimates are generally highly significant.

Because our study examines the performance of factor models in different market trends, we also run time-series regressions for each sub-sample period. The sub-sample regression results are summarised in Table 5. Here, the adjusted $R^{2}$ in all sub-periods presents the same patterns as in the full period, but the number of significant intercepts not. For example, in the first subperiod of the bull market, adding more factors increases the degree of significance for the estimated intercepts. We will discuss the possible explanation for this finding in the next sub-section. The

\footnotetext{
${ }^{6}$ The rule for choosing the lag parameter $q$ is that $q=0.75 \times \sqrt[3]{T}$, rounded to an integer, where $T$ is the number of observations used in the regression (see Stock and Watson, 2007, page 607).
} 
standard deviation of the intercepts decreases with more factors added.

Comparing across different sub-periods, the adjusted $R^{2}$ tends to be larger in the bear markets than in the bull and consolidation markets. Roll (1988) initially claims that the $R^{2}$ from a timeseries regression of the stock return on the market portfolio can be treated as a measure of stock price synchronicity. That is, a high $R^{2}$ in such a regression indicates a high degree of stock price synchronicity. Likewise, we expect a higher degree of stock price co-movements in the crash. Roll (1988) and Morck et al. (2000) document that stock prices move together more in poorly developed markets than in developed markets. So it is not surprising that the adjusted $R^{2}$ looks higher in the Chinese market than in the US and the UK.

Furthermore, the high adjusted $R^{2}$ here is also partly attributed to the higher data frequency, i.e., daily versus monthly data. We also compare the adjusted $R^{2}$ of regressions using daily and monthly returns. We find that the adjusted $R^{2}$ is slightly higher when using daily returns in both China and the US within the same sample period as this study. ${ }^{7}$

\subsection{GRS test and related performance metrics}

In addition to the time-series regressions, we also evaluate the models based on some performance measures, including two $G R S$-test related measures, five measures that are related to the intercept, one $R^{2}$ related measure, and a new measure of squared shape ratio for factors. Moreover, we also provide explanation for the above finding that adding more factors into the models produces more significant alphas in some sub-periods.

\subsubsection{GRS test}

After the time-series regression tests, we also perform the GRS test (Gibbons et al., 1989) to formally test the null hypothesis that the intercepts for the 25 portfolios are jointly zero in the above models. The GRS test statistic is defined as:

$$
G R S \equiv\left(\frac{T-N-K}{N}\right)\left[\frac{\hat{\alpha}^{\prime} \hat{\Sigma}^{-1} \hat{\alpha}}{1+E_{T}(f)^{\prime} \operatorname{Var}_{T}(f)^{-1} E_{T}(f)}\right] \sim F(N, T-N-K)
$$

where $T$ is the number of observations in the time-series; $N$ is the number of LHS assets; $K$ is the number of factors; $E_{T}(f)$ is the sample mean of the factors; $\operatorname{Var}_{T}(f)$ is their estimated variance-covariance matrix; $\hat{\alpha}$ is an $N \times 1$ vector of estimated intercepts from the individual timeseries regressions; and $\hat{\Sigma}$ is the estimated variance-covariance matrix of the intercepts. A normal distribution is assumed to derive the GRS statistic. If the null hypothesis holds, then the GRS statistic should be equal to zero. For a specific $G R S$ statistic, $p(G R S)$ reports the corresponding $p$-value.

\subsubsection{Selected performance metrics}

In addition to the $G R S$ statistic, we also report selected conventional metrics on model performance focusing on the intercepts (together with the average adjusted $R^{2}$ for convenience of comparison) and a recently proposed metric focusing on the factors. The former include $A\left(\alpha_{i}\right), A\left(s e_{i}\right), A\left|\alpha_{i}\right|$, $S h(\alpha), A\left|\alpha_{i}\right| / A\left|\bar{r}_{i}\right|$, and $A\left(R_{i}^{2}\right)$, which are commonly employed in the literature, e.g., Fama and French $(2015,2016,2017)$. Here, $A$ is used to indicate an average value. $A\left(\alpha_{i}\right)$ is the average intercept, and $A\left(R_{i}^{2}\right)$ is the average adjusted $\mathrm{R}$-squared. We include them with other metrics in order to allow for a convenient comparison. $A\left(s e_{i}\right)$ is the average standard error of the intercepts;

\footnotetext{
${ }^{7}$ These results are not explicitly reported in this paper for brevity.
} 
Table 5: Summary of the sub-sample time-series regression results

\begin{tabular}{|c|c|c|c|c|c|c|c|c|c|c|c|c|c|c|c|}
\hline & \multicolumn{3}{|c|}{ CAPM } & \multicolumn{5}{|c|}{ FF3 } & \multicolumn{7}{|c|}{ FF5 } \\
\hline & $\alpha$ & $\beta_{M}$ & $\operatorname{adj} R^{2}$ & $\alpha$ & $\beta_{M}$ & $\beta_{S}$ & $\beta_{H}$ & $\operatorname{adj} R^{2}$ & $\alpha$ & $\beta_{M}$ & $\beta_{S}$ & $\beta_{H}$ & $\beta_{R}$ & $\beta_{C}$ & $\operatorname{adj} R^{2}$ \\
\hline \multicolumn{16}{|c|}{ Panel A: Sub-period 1 (Bull), Dec 1, 2006 to Oct 31, 2007, $T=221$} \\
\hline Mean & -0.053 & 1.063 & 0.857 & -0.033 & 1.038 & 0.645 & 0.101 & 0.947 & -0.043 & 1.046 & 0.612 & 0.091 & 0.052 & 0.155 & 0.948 \\
\hline Std. Dev. & 0.055 & 0.081 & 0.060 & 0.055 & 0.075 & 0.493 & 0.374 & 0.020 & 0.049 & 0.071 & 0.475 & 0.380 & 0.121 & 0.135 & 0.018 \\
\hline Med & -0.064 & 1.091 & 0.866 & -0.036 & 1.050 & 0.866 & 0.055 & 0.948 & -0.041 & 1.062 & 0.753 & 0.069 & 0.046 & 0.140 & 0.949 \\
\hline Min & -0.128 & 0.838 & 0.651 & -0.135 & 0.811 & -0.590 & -0.770 & 0.881 & -0.146 & 0.853 & -0.377 & -0.776 & -0.175 & -0.090 & 0.898 \\
\hline Max & 0.097 & 1.150 & 0.924 & 0.127 & 1.161 & 1.227 & 1.190 & 0.971 & 0.081 & 1.171 & 1.199 & 1.245 & 0.422 & 0.557 & 0.972 \\
\hline $0 \sim 1 \%$ & 0 & 25 & & 1 & 25 & 23 & 13 & & 1 & 25 & 23 & 13 & 1 & 3 & \\
\hline $1 \sim 5 \%$ & 1 & 0 & & 3 & 0 & 0 & 3 & & 1 & 0 & 0 & 4 & 1 & 4 & \\
\hline $5 \sim 10 \%$ & 0 & 0 & & 4 & 0 & 0 & 2 & & 6 & 0 & 1 & 1 & 1 & 3 & \\
\hline \multicolumn{16}{|c|}{ Panel B: Sub-period 2 (Bear), Nov 1, 2007 to Nov 4, 2008, T=247 } \\
\hline Mean & 0.094 & 1.042 & 0.902 & -0.004 & 1.010 & 0.802 & 0.101 & 0.960 & 0.018 & 1.053 & 0.690 & 0.021 & 0.261 & 0.579 & 0.966 \\
\hline Std. Dev. & 0.071 & 0.046 & 0.035 & 0.030 & 0.039 & 0.492 & 0.337 & 0.011 & 0.031 & 0.042 & 0.492 & 0.338 & 0.104 & 0.098 & 0.010 \\
\hline Med & 0.098 & 1.046 & 0.902 & -0.008 & 1.007 & 0.978 & 0.102 & 0.963 & 0.012 & 1.050 & 0.861 & 0.008 & 0.268 & 0.558 & 0.969 \\
\hline Min & -0.066 & 0.933 & 0.817 & -0.056 & 0.925 & -0.379 & -0.727 & 0.933 & -0.028 & 0.976 & -0.433 & -0.790 & 0.048 & 0.441 & 0.941 \\
\hline Max & 0.192 & 1.115 & 0.961 & 0.064 & 1.082 & 1.306 & 0.976 & 0.973 & 0.090 & 1.132 & 1.308 & 0.902 & 0.436 & 0.829 & 0.977 \\
\hline $0 \sim 1 \%$ & 0 & 25 & & 0 & 25 & 22 & 13 & & 0 & 25 & 22 & 15 & 11 & 25 & \\
\hline $1 \sim 5 \%$ & 4 & 0 & & 0 & 0 & 0 & 3 & & 1 & 0 & 0 & 1 & 5 & 0 & \\
\hline $5 \sim 10 \%$ & 5 & 0 & & 0 & 0 & 1 & 2 & & 0 & 0 & 0 & 1 & 3 & 0 & \\
\hline \multicolumn{16}{|c|}{ Panel C: Sub-period 3 (Consolidation), Nov 5, 2008 to Oct 27, 2014, T=1450 } \\
\hline Mean & 0.045 & 1.104 & 0.844 & -0.009 & 1.044 & 0.684 & -0.172 & 0.942 & -0.008 & 1.053 & 0.643 & -0.189 & 0.043 & 0.242 & 0.944 \\
\hline Std. Dev. & 0.041 & 0.058 & 0.046 & 0.014 & 0.042 & 0.468 & 0.363 & 0.012 & 0.014 & 0.042 & 0.467 & 0.361 & 0.072 & 0.119 & 0.011 \\
\hline Med & 0.056 & 1.127 & 0.839 & -0.012 & 1.040 & 0.854 & -0.170 & 0.945 & -0.012 & 1.050 & 0.803 & -0.198 & 0.050 & 0.220 & 0.948 \\
\hline Min & -0.037 & 0.965 & 0.769 & -0.030 & 0.980 & -0.226 & -1.122 & 0.907 & -0.029 & 0.989 & -0.313 & -1.118 & -0.102 & 0.020 & 0.915 \\
\hline Max & 0.115 & 1.177 & 0.921 & 0.029 & 1.132 & 1.208 & 0.586 & 0.955 & 0.030 & 1.139 & 1.223 & 0.564 & 0.248 & 0.499 & 0.957 \\
\hline $0 \sim 1 \%$ & 13 & 25 & & 2 & 25 & 24 & 22 & & 1 & 25 & 24 & 22 & 2 & 21 & \\
\hline $1 \sim 5 \%$ & 4 & 0 & & 3 & 0 & 0 & 0 & & 3 & 0 & 0 & 0 & 6 & 1 & \\
\hline $5 \sim 10 \%$ & 1 & 0 & & 2 & 0 & 0 & 1 & & 3 & 0 & 0 & 0 & 0 & 1 & \\
\hline \multicolumn{16}{|c|}{ Panel D: Sub-period 4 (Bull), Oct 28, 2014 to Jun 12, 2015, T=155 } \\
\hline Mean & 0.156 & 0.876 & 0.589 & -0.005 & 1.022 & 0.667 & -0.330 & 0.893 & -0.033 & 1.018 & 0.423 & -0.476 & -0.357 & 0.572 & 0.915 \\
\hline Std. Dev. & 0.117 & 0.100 & 0.136 & 0.062 & 0.038 & 0.490 & 0.430 & 0.042 & 0.060 & 0.036 & 0.490 & 0.395 & 0.130 & 0.220 & 0.034 \\
\hline Med & 0.146 & 0.849 & 0.570 & -0.027 & 1.022 & 0.812 & -0.292 & 0.900 & -0.058 & 1.019 & 0.541 & -0.429 & -0.360 & 0.562 & 0.922 \\
\hline Min & -0.139 & 0.751 & 0.379 & -0.078 & 0.920 & -0.322 & -1.239 & 0.737 & -0.105 & 0.913 & -0.657 & -1.299 & -0.621 & 0.212 & 0.794 \\
\hline Max & 0.373 & 1.169 & 0.855 & 0.167 & 1.081 & 1.197 & 0.722 & 0.961 & 0.118 & 1.078 & 1.053 & 0.469 & -0.043 & 1.091 & 0.975 \\
\hline $0 \sim 1 \%$ & 0 & 25 & & 0 & 25 & 21 & 16 & & 0 & 25 & 24 & 17 & 7 & 16 & \\
\hline $1 \sim 5 \%$ & 3 & 0 & & 0 & 0 & 1 & 6 & & 1 & 0 & 0 & 3 & 11 & 4 & \\
\hline $5 \sim 10 \%$ & 3 & 0 & & 0 & 0 & 2 & 0 & & 0 & 0 & 1 & 1 & 3 & 2 & \\
\hline \multicolumn{16}{|c|}{ Panel E: Sub-period 5 (Bear), Jun 13, 2015 to Jan 28, 2016, T=155 } \\
\hline Mean & 0.125 & 1.251 & 0.877 & -0.026 & 1.084 & 0.786 & -0.259 & 0.975 & 0.027 & 1.066 & 0.471 & -0.331 & -0.233 & 0.353 & 0.979 \\
\hline Std. Dev. & 0.096 & 0.099 & 0.042 & 0.055 & 0.040 & 0.467 & 0.385 & 0.011 & 0.053 & 0.032 & 0.500 & 0.363 & 0.197 & 0.225 & 0.008 \\
\hline Med & 0.108 & 1.287 & 0.863 & -0.034 & 1.093 & 0.938 & -0.280 & 0.977 & 0.030 & 1.071 & 0.642 & -0.359 & -0.232 & 0.298 & 0.979 \\
\hline Min & -0.033 & 0.896 & 0.804 & -0.124 & 0.977 & -0.189 & -1.119 & 0.948 & -0.070 & 0.979 & -0.566 & -1.158 & -0.624 & -0.082 & 0.960 \\
\hline Max & 0.280 & 1.338 & 0.963 & 0.070 & 1.153 & 1.241 & 0.681 & 0.989 & 0.112 & 1.111 & 1.016 & 0.499 & 0.283 & 0.907 & 0.990 \\
\hline $0 \sim 1 \%$ & 0 & 25 & & 0 & 25 & 21 & 15 & & 0 & 25 & 19 & 14 & 3 & 9 & \\
\hline $1 \sim 5 \%$ & 0 & 0 & & 1 & 0 & 2 & 1 & & 2 & 0 & 3 & 1 & 3 & 5 & \\
\hline $5 \sim 10 \%$ & 0 & 0 & & 0 & 0 & 0 & 1 & & 1 & 0 & 2 & 2 & 2 & 2 & \\
\hline \multicolumn{16}{|c|}{ Panel F: Sub-period 6 (Consolidation), Jan 29, 2016 to Nov 30, 2016, T=203 } \\
\hline Mean & 0.006 & 1.255 & 0.903 & -0.026 & 1.074 & 0.602 & -0.185 & 0.968 & -0.017 & 1.071 & 0.484 & -0.272 & -0.052 & 0.206 & 0.970 \\
\hline Std. Dev. & 0.047 & 0.142 & 0.035 & 0.025 & 0.047 & 0.491 & 0.390 & 0.008 & 0.023 & 0.038 & 0.500 & 0.366 & 0.146 & 0.164 & 0.007 \\
\hline Med & 0.006 & 1.317 & 0.898 & -0.033 & 1.076 & 0.711 & -0.105 & 0.971 & -0.019 & 1.069 & 0.538 & -0.242 & -0.083 & 0.223 & 0.972 \\
\hline Min & -0.076 & 0.786 & 0.829 & -0.069 & 0.974 & -0.312 & -0.909 & 0.950 & -0.050 & 0.992 & -0.357 & -1.007 & -0.388 & -0.121 & 0.950 \\
\hline $\operatorname{Max}$ & 0.104 & 1.423 & 0.950 & 0.030 & 1.152 & 1.312 & 0.656 & 0.983 & 0.039 & 1.137 & 1.157 & 0.600 & 0.228 & 0.509 & 0.984 \\
\hline $0 \sim 1 \%$ & 0 & 25 & & 0 & 25 & 21 & 15 & & 0 & 25 & 19 & 15 & 2 & 9 & \\
\hline $1 \sim 5 \%$ & 1 & 0 & & 2 & 0 & 1 & 1 & & 1 & 0 & 4 & 4 & 2 & 3 & \\
\hline $5 \sim 10 \%$ & 1 & 0 & & 5 & 0 & 1 & 2 & & 1 & 0 & 0 & 1 & 1 & 4 & \\
\hline
\end{tabular}

This table summarises the results of the 25 time-series regressions within six sub-periods delineated by market trends. For each model, we report the mean, standard deviation, median, minimum and maximum values for each estimated coefficient (i.e., factor loading or exposure) and adjusted $R^{2}$ across the 25 regressions. The intercept, $\alpha$, is in percent. The rows of " $0 \sim 1 \%$ ", " $1 \sim 5 \%$ " and " $5 \sim 10 \%$ " report the numbers of significant corresponding coefficients at the $1 \%$ level, between the $1 \%$ and $5 \%$ levels and between the $5 \%$ and $10 \%$ levels, respectively. 
$A\left|\alpha_{i}\right|$ is the average absolute value of the intercepts; and $S h(\alpha)$ is the Sharpe ratio for the vector of intercepts from regressions of the LHS returns on a model's factors. $A\left|\alpha_{i}\right| / A\left|\bar{r}_{i}\right|$ is the average absolute intercept over the average absolute value of $\bar{r}_{i}$, which is first shown in Fama and French $(2015){ }^{8}$

Inspired by Barillas and Shanken (2016) and Fama and French (2018), we also evaluate the pricing models on a relatively new performance metric, $S h^{2}(f)$, i.e., the squared Sharpe ratios of the models' factor sets. It focuses on the vector of model's factors but with links to the abovementioned performance measures: GRS statistic and $S h^{2}(\alpha)$. Barillas and Shanken (2016) recently proposed a new performance metric, $S h^{2}(f)$. They suggested that, in principle, the factors should explain not only the universe of conventional LHS assets but also all potential factors, with linearly dependent components deleted. Thus, we can expect that $S h^{2}(f)$ is negatively related to the $G R S$ statistic and $S h^{2}(\alpha)$.

As shown in Gibbons et al. (1989), the numerator of the GRS statistic, $\alpha^{\prime} \Sigma^{-1} \alpha$, also defined as the squared Sharpe ratio for the intercepts, $S h^{2}(\alpha)$, can be written as

$$
\alpha^{\prime} \Sigma^{-1} \alpha \equiv S h^{2}(\alpha)=S h^{2}(R, f)-S h^{2}(f)
$$

where $R$ represents a set of assets on the LHS of model equations. $f$ stands for the factor(s), which is a scalar if only one factor is included in the model, and a vector when more than one factor is included. If the set of LHS assets, $R$, includes all assets (including the potential factors), then $S h^{2}(R, f)=S h^{2}(R)$. So all variation in $S h^{2}(\alpha)$ across models is due to $S h^{2}(f)$, and $S h^{2}(\alpha)$ and $S h^{2}(f)$ are perfectly negatively correlated. Therefore, minimising $\alpha^{\prime} \Sigma^{-1} \alpha$ is equivalent to maximising $S h^{2}(f)$. This relation needs not be perfect for a subset of LHS assets, however, because there is variation across models in $S h^{2}(R, f)$ not linearly related to $S h^{2}(f)$.

Similarly, the GRS statistic can be written, in Sharpe ratio form, as:

$$
\begin{aligned}
G R S & =\gamma\left(\frac{S h^{2}(\alpha)}{1+S h^{2}(f)}\right)=\gamma\left(\frac{S h^{2}(R, f)-S h^{2}(f)}{1+S h^{2}(f)}\right) \\
& =\gamma\left(\frac{1+S h^{2}(R, f)}{1+S h^{2}(f)}-1\right)
\end{aligned}
$$

where $\gamma$ is a scalar depending on the number of observations $(T)$, factors $(K)$, and LHS portfolios $(N)$. Within the same sample period and with the same LHS portfolios, if we compare among the nested models, then the number of factors $(K)$ influences $\gamma$. This influence is generally negligible though, if we limit the number of factors in a model. As in Equation (3), if $R$ includes all assets, $S h^{2}(R, f)=S h^{2}(R)$, so all variation in $G R S$ across models is due to $S h^{2}(f)$, and $G R S$ and $S h^{2}(f)$ are perfectly negatively related. Then, minimising the $G R S$ statistic is equivalent to maximising $S h^{2}(f)$. As with $S h^{2}(\alpha)$ in Equation (3), the cross-model variation in $S h^{2}(R, f)$ and $S h^{2}(f)$ drives the variation in $G R S$. Again, the variation in $S h^{2}(R, f)$ not linearly related to $S h^{2}(f)$ causes a less than perfect negative relation between $G R S$ and $S h^{2}(f)$. The arguments in this and the previous paragraphs provide an explanation for the above finding that adding more factors into the models could produce more significant alphas in some sub-periods, for the 25 size-B/M sorted portfolios are a subset of the universe of all possible LHS portfolios.

Another attractive feature of $S h^{2}(f)$ as a model performance metric is that it can be used to measure the (marginal) contribution of the factor(s) to the model's performance, regardless of whether or not the LHS portfolios are all possible assets in practice. The marginal contribution

\footnotetext{
${ }^{8}$ To estimate the cross-section dispersion in average returns missed by a model, Fama and French (2015) define $R_{i}$ as the time-series average excess return on portfolio $i ; \bar{R}$ as the cross-section average of $\bar{R}_{i}$; and $\bar{r}_{i}$ as portfolio $i$ 's deviation from the cross-section average, $\bar{r}_{i}=\bar{R}_{i}-\bar{R}$.
} 
of a factor to a model is measured as the increment in $S h^{2}(f)$ when that factor is added to the model's set of factors. (Fama and French, 2018)

Based on the above discussion, a low value of $A\left(\alpha_{i}\right), G R S$ statistic, $A\left(s e_{i}\right), A\left|\alpha_{i}\right|$, or $A\left|\alpha_{i}\right| / A\left|\bar{r}_{i}\right|$ indicates a good performance of factor models, while good performance is also suggested by a high value of $p(G R S), A\left(R_{i}^{2}\right)$, or $S h^{2}(f)$. As mentioned above, a model that produces the highest $S h^{2}(f)$ must produce the lowest $S h^{2}(\alpha)$ and $G R S$ statistic in tests with the inclusion of all possible LHS assets. This perfect negative relationship is not always applied for subsets of all possible assets, however, as we can see, for example, in our 25 LHS anomaly portfolios reported in Table 6.

Table 6 presents the results for the GRS test and selected performance metrics for the full period and the six sub-periods. The GRS test can easily reject the three models for all LHS portfolios and RHS factors considered in our study. If it rejects, then we look at the smaller magnitude of the GRS statistic. As for the full sample period, the rankings of the three models based on all the performance metrics are consistent. That is, the FF5 outperforms the FF3, and the FF3 outperforms the CAPM. This is not applied for all six sub-periods, however. The ranking of the three models on $S h^{2}(f)$ is consistent with the ranking on the adjusted $R^{2}$ in all periods. Measured by $S h^{2}(f)$, in the full period and the six sub-periods, the market factor alone can hardly explain the LHS returns. The marginal contribution of additional pairs of factors (i.e., pair of size and value factors and pair of profitability and investment factors) is high.

Nevertheless, for the six sub-periods, when the rankings are based on other intercept performance metrics, inconsistent conclusions are reached. Taking the first bull market (Panel B) as the example, the ranking on the GRS statistic and the corresponding $p$-value is the FF5 over the CAPM over the FF3, while on $S h(\alpha)$ it is the CAPM over the FF5 over the FF3. The metric of $A|\alpha| / A|r|$ shows a different ranking of the FF3 over the FF5 over the CAPM. ${ }^{9}$ Thus, the common intercept performance metrics might not be good measurements in practice if the LHS portfolios are a subset of the universe of assets, on account of their inconsistency in ranking the three models in some sub-periods.

\section{Fama-MacBeth regressions}

In addition to the above time-series analysis, we also examine the models based on the two-stage approach of Fama and MacBeth (1973). Because our 25 portfolios provide large cross-sectional variation in average returns, for simplicity, we do not re-rank the stocks by their pre-ranking betas to construct new portfolios as in Fama and MacBeth (1973). Instead, we directly use the slope coefficients obtained from the above time-series regression as the first-stage estimates of factor betas for the individual portfolios. Then, taking the FF5 as an example, in the second stage, we run the following cross-sectional regression on each trading day $t$ :

$$
R_{i t}-R_{f t}=\gamma_{0, t}+\gamma_{M, t} \hat{\beta}_{M, i}+\gamma_{S, t} \hat{\beta}_{S, i}+\gamma_{H, t} \hat{\beta}_{H, i}+\gamma_{R, t} \hat{\beta}_{R, i}+\gamma_{C, t} \hat{\beta}_{C, i}+\epsilon_{i t}, i=1, \ldots, N
$$

\footnotetext{
${ }^{9}$ The inconsistent ranking of factor models based on the metrics focusing on the intercepts is also reported in Fama and French (2018).
} 
Table 6: GRS tests and other performance metrics

\begin{tabular}{|c|c|c|c|c|c|c|c|c|c|}
\hline & $A(\alpha)$ & $G R S$ & $p(G R S)$ & $A\left(R^{2}\right)$ & $A(s e)$ & $A|\alpha|$ & $\operatorname{Sh}(\alpha)$ & $A|\alpha| / A|\bar{r}|$ & $S h^{2}(f)$ \\
\hline \multicolumn{10}{|c|}{ Panel A: Full sample Dec 1, 2006 to Nov 30, 2016} \\
\hline CAPM & 0.040 & 3.835 & 0.000 & 0.849 & 0.019 & 0.045 & 0.200 & 1.328 & 0.001 \\
\hline FF3 & -0.016 & 2.937 & 0.000 & 0.950 & 0.011 & 0.021 & 0.176 & 0.623 & 0.010 \\
\hline FF5 & -0.012 & 2.815 & 0.000 & 0.953 & 0.010 & 0.019 & 0.172 & 0.569 & 0.013 \\
\hline \multicolumn{10}{|c|}{ Panel B: Sub-period 1 (Bull), Dec 1, 2006 to Oct 31, 2007, T=221 } \\
\hline CAPM & -0.053 & 0.967 & 0.514 & 0.857 & 0.071 & 0.067 & 0.361 & 1.947 & 0.053 \\
\hline FF3 & -0.033 & 1.025 & 0.436 & 0.947 & 0.043 & 0.052 & 0.375 & 1.508 & 0.060 \\
\hline FF5 & -0.043 & 0.952 & 0.533 & 0.948 & 0.043 & 0.054 & 0.367 & 1.557 & 0.082 \\
\hline \multicolumn{10}{|c|}{ Panel C: Sub-period 2 (Bear), Nov 1, 2007 to Nov 4, 2008, T=247 } \\
\hline CAPM & 0.094 & 0.867 & 0.650 & 0.902 & 0.066 & 0.104 & 0.317 & 1.877 & 0.023 \\
\hline FF3 & -0.004 & 0.634 & 0.912 & 0.960 & 0.043 & 0.024 & 0.276 & 0.430 & 0.055 \\
\hline FF5 & 0.018 & 0.621 & 0.921 & 0.966 & 0.040 & 0.027 & 0.279 & 0.484 & 0.088 \\
\hline \multicolumn{10}{|c|}{ Panel D: Sub-period 3 (Consolidation), Nov 5, 2008 to Oct 27, 2014, T=1450 } \\
\hline CAPM & 0.045 & 2.264 & 0.000 & 0.844 & 0.019 & 0.052 & 0.199 & 1.513 & 0.001 \\
\hline FF3 & -0.009 & 1.494 & 0.056 & 0.942 & 0.011 & 0.014 & 0.163 & 0.424 & 0.016 \\
\hline FF5 & -0.008 & 1.484 & 0.059 & 0.944 & 0.011 & 0.014 & 0.163 & 0.410 & 0.016 \\
\hline \multicolumn{10}{|c|}{ Panel E: Sub-period 4 (Bull), Oct 28, 2014 to Jun 12, 2015, T=155 } \\
\hline CAPM & 0.156 & 1.347 & 0.144 & 0.588 & 0.110 & 0.169 & 0.537 & 2.829 & 0.105 \\
\hline FF3 & -0.005 & 1.184 & 0.266 & 0.893 & 0.057 & 0.050 & 0.515 & 0.840 & 0.136 \\
\hline FF5 & -0.033 & 1.116 & 0.335 & 0.915 & 0.051 & 0.060 & 0.506 & 1.000 & 0.145 \\
\hline \multicolumn{10}{|c|}{ Panel F: Sub-period 5 (Bear), Jun 13, 2015 to Jan 28, 2016, T=155 } \\
\hline CAPM & 0.125 & 1.629 & 0.042 & 0.877 & 0.126 & 0.129 & 0.566 & 2.047 & 0.015 \\
\hline FF3 & -0.026 & 1.812 & 0.018 & 0.975 & 0.056 & 0.052 & 0.606 & 0.822 & 0.029 \\
\hline FF5 & 0.027 & 1.913 & 0.011 & 0.979 & 0.053 & 0.049 & 0.647 & 0.771 & 0.096 \\
\hline \multicolumn{10}{|c|}{ Panel G: Sub-period 6 (Consolidation), Jan 29, 2016 to Nov 30, 2016, T=203 } \\
\hline CAPM & 0.006 & 1.641 & 0.035 & 0.903 & 0.039 & 0.038 & 0.484 & 0.866 & 0.009 \\
\hline FF3 & -0.026 & 1.232 & 0.217 & 0.968 & 0.023 & 0.031 & 0.434 & 0.703 & 0.072 \\
\hline FF5 & -0.017 & 1.051 & 0.405 & 0.970 & 0.023 & 0.025 & 0.408 & 0.561 & 0.098 \\
\hline
\end{tabular}

This table reports the results of performance metrics on the three factor models, i.e., the CAPM, the FF3 and the FF5, within the full sample period and the six sub-periods separated based on market trends. GRS reports the $G R S$ statistic and $p(G R S)$ is the $p$-value for the corresponding $G R S$ statistic. $A$ is used to indicate an average value. $A(\alpha)$ is the average intercept; $A\left(R^{2}\right)$ is the average adjusted R-squared; $A(s e)$ is the average standard error of the intercepts; $A|\alpha|$ is the average absolute value of the intercepts; $S h(\alpha)$ is the Sharpe ratio for the vector of intercepts from regressions of the LHS returns on a model's factors; $A|\alpha| / A|\bar{r}|$ is the average absolute intercept over the average absolute value of $\bar{r}$, which is first shown in Fama and French (2015); and $S h^{2}(f)$ is a newly proposed metric of the squared Sharpe ratio for the models' factor sets. 
Next, the factor premiums are estimated as the time-series average of $\hat{\gamma}_{M, t}, \hat{\gamma}_{S, t}, \hat{\gamma}_{H, t}, \hat{\gamma}_{R, t}$ and $\hat{\gamma}_{C, t}$. That is,

$$
\begin{aligned}
& \hat{\gamma}_{M}=\frac{1}{T} \sum_{t=1}^{T} \hat{\gamma}_{M, t} \\
& \hat{\gamma}_{S}=\frac{1}{T} \sum_{t=1}^{T} \hat{\gamma}_{S, t} \\
& \hat{\gamma}_{H}=\frac{1}{T} \sum_{t=1}^{T} \hat{\gamma}_{H, t} \\
& \hat{\gamma}_{R}=\frac{1}{T} \sum_{t=1}^{T} \hat{\gamma}_{R, t} \\
& \hat{\gamma}_{C}=\frac{1}{T} \sum_{t=1}^{T} \hat{\gamma}_{C, t}
\end{aligned}
$$

Note that the original Fama-MacBeth regressions provide standard errors corrected only for cross-sectional correlation, but not for time-series autocorrelation. Instead, as recommended by Petersen (2009), we use the Newey-West standard errors which are robust to heteroskedasticity and autocorrelation (HAC), even though this is usually not a problem for daily returns. ${ }^{10}$

For the cross-period comparison, we follow Lettau and Ludvigson (2001) and Petkova (2006) and report the adjusted $R^{2}$ from a single cross-sectional regression of returns averaged over time. In other words, the second step with $T$ regressions is replaced by a single regression of $N$ portfolio returns, averaged over time, against $K$ factor exposures with sample size $N$ :

$$
E_{T}\left(R_{i}-R_{f}\right)=\gamma_{0}+\gamma_{M} \hat{\beta}_{i M}+\gamma_{S} \hat{\beta}_{i S}+\gamma_{H} \hat{\beta}_{i H}+\gamma_{R} \hat{\beta}_{i R}+\gamma_{C} \hat{\beta}_{i C}+\epsilon_{i}, i=1, \ldots, N
$$

where $E_{T}\left(R_{i}-R_{f}\right)$ is the average return over time of each portfolio or asset return, the factor exposures $\hat{\beta}_{i}$ are the same as in Equation (5), and $i$ goes from 1 through $N$. The coefficients $\hat{\gamma}$ will be the same in both cases as long as $\hat{\beta}$ s are constant over the selected sample period, which is true in our study. ${ }^{11}$ We will focus more on the adjusted $R^{2}$ in this section for our purpose of comparing model performance across different sub-periods.

Table 7 reports the results for the second stage of the Fama-MacBeth regression over the full sample period and the six sub-periods. Within the full, and all sub-periods, the adjusted $R^{2}$ from the cross-sectional regression of LHS returns on the market factor loading alone is very small. Adding additional factors mainly serves to increase the cross-sectional $R^{2}$. This suggests again that the CAPM is unable to explain the LHS returns. As such, even though the estimated intercept is generally insignificant for the CAPM, the relatively smaller intercept of the CAPM makes less sense because the adjusted $R^{2}$ is too small. The cross-sectional adjusted $R^{2}$ s for the FF3 and the FF5 are close to each other and much higher than that for the CAPM. The adjusted $R^{2}$ is slightly larger for the FF5 in the bull and consolidation markets, while slightly smaller in the bear markets. So, it should be more meaningful to compare the estimated intercepts of the FF3 and the FF5. For these two models, we find that the $t$-statistics for the estimated intercepts are smaller for the FF5 than those for the FF3 in all sub-periods. The evidence suggests that the FF5 is superior vis-a-vis the other two models in explaining the cross-sectional variations in the 25 portfolio returns.

Comparing the trending (i.e., bull and bear) and the consolidation markets, it is somewhat surprising, at first glance, that the cross-sectional $R^{2}$ tends to be much smaller in the trending markets. Recall that the time-series regressions show that the models can better explain the time-

\footnotetext{
${ }^{10}$ Fama and French (1988) claim that stocks have weak time-series autocorrelation in daily and weekly holding periods, but autocorrelation is stronger over long horizons.

${ }^{11}$ The typically-reported standard errors and $t$-stats will, of course, not be the same because in Equation (7) the factor premiums, $\gamma \mathrm{s}$, are not estimated with the same time-averaging techniques of the Fama-MacBeth method. Remember that the Newey-West (HAC) standard errors should be used to test the significance of $\hat{\gamma}$ s. Equation (7) is only used to obtain the cross-section adjusted $R^{2}$.
} 
series variations in the portfolio excess returns in the crashes, as suggested by the higher timeseries $R^{2}$. The much smaller cross-sectional adjusted $R^{2}$ in the trending markets suggests that the models have more difficulty explaining the cross-sectional variations in the portfolio returns when the market is in the crashes and booms. We try to investigate the possible reasons for these ostensibly contradictory findings by conducting the instability test on the models in the following section.

\section{Model instability analysis}

In this section, we examine the stability of the factor models and their parameters. We first conduct an instability test based on Hansen's (1992) statistics for linear models. Then, we run the recursive regressions over the whole sample period with a starting window of 20 trading days, i.e., approximately a calendar month and plot the changes in parameters over time.

\subsection{Hansen's instability test}

Hansen's instability test extends Nyblom's (1989) Lagrange multiplier test for the constancy of all parameters as a whole to individual coefficients. Thus, unlike Nyblom's test, which can only be used to examine the model's overall instability, Hansen's method can also test the instability for each model coefficient.

For the individual coefficient tests, the null hypothesis is that each of the parameters, including the intercept, the slope(s), and the error variance, is constant, i.e., $H_{0}: \beta_{i}$ is constant for $i=1, \ldots, k$ or $H_{0}: \sigma^{2}$ is constant. The corresponding test statistic is:

$$
L_{i}=\frac{1}{n V_{i}} \sum_{t=1}^{n} S_{i t}^{2}, i=1, \ldots, k
$$

where $V_{i}=\sum_{t=1}^{n} f_{i t}^{2}, f_{i t}=\left\{\begin{array}{ll}x_{i t} \hat{\varepsilon}_{t} & i=1, \ldots, k \\ \hat{\varepsilon}_{t}^{2}-\hat{\sigma}^{2} & i=k+1\end{array}\right.$, and by assumption, $\sum_{t=1}^{n} f_{i t}=0$ for $i=1, \ldots, k+1$, and $S_{i t}=\sum_{j=1}^{t} f_{i j}, i=1, \ldots, k+1$. The limiting distribution of $L_{i}$ under the null is a Cramer-von Mises distribution,

$$
L_{i} \Rightarrow \int_{0}^{1} B_{1}^{u}(\lambda) B_{1}^{u}(\lambda) d \lambda
$$

Similarly, for testing the joint hypothesis that all parameters are jointly constant, i.e., $H_{0}: \boldsymbol{\beta}$ and $\sigma^{2}$ are constant, the statistic is:

$$
L_{c}=\frac{1}{n} \sum_{t=1}^{n} \mathbf{S}_{t}^{\prime} \mathbf{V}^{-1} \mathbf{S}_{t}=\frac{1}{n} \operatorname{tr}\left(\mathbf{V}^{-1} \sum_{t=1}^{n} \mathbf{S}_{t}^{\prime} \mathbf{S}_{t}\right)
$$

where $\mathbf{V}=\sum_{t=1}^{n} \mathbf{f}_{t} \mathbf{f}_{t}^{\prime}, \mathbf{f}_{t}=\left(f_{i t}, \ldots, f_{k+1, t}\right)^{\prime}$, and $\mathbf{S}_{t}=\left(S_{i t}, \ldots, S_{k+1, t}\right)^{\prime}$. Under the null of nostructural change in the model,

$$
L_{c} \Rightarrow \int_{0}^{1} \mathbf{B}_{k+1}^{u}(\lambda) \mathbf{B}_{k+1}^{u}(\lambda) d \lambda
$$

where $\mathbf{B}_{k+1}^{u}(\lambda)=\mathbf{W}_{k+1}(\lambda)-\lambda \mathbf{W}_{k+1}(1)$, and $\mathbf{W}_{k+1}(\lambda)$ is $k+1$ dimensional Brownian motion. In both cases, we reject the null hypothesis if the statistic, $L_{i}$ or $L_{c}$, is greater than the corresponding 
Table 7: Results for the second stage of the Fama-MacBeth regressions

\begin{tabular}{|c|c|c|c|c|c|c|c|}
\hline & $\gamma_{0}$ & $\gamma_{M}$ & $\gamma_{S}$ & $\gamma_{H}$ & $\gamma_{R}$ & $\gamma_{C}$ & $\operatorname{Adj} R^{2}$ \\
\hline \multicolumn{8}{|c|}{ Panel A: Full sample, Dec 1, 2006 to Nov 30, 2016, T=2431 } \\
\hline \multirow[t]{2}{*}{ CAPM } & -0.260 & $0.331^{*}$ & & & & & 0.121 \\
\hline & $(-1.28)$ & $(1.82)$ & & & & & \\
\hline \multirow[t]{2}{*}{ FF3 } & $0.334^{* * *}$ & $-0.276 * * *$ & $0.077^{* * *}$ & -0.004 & & & 0.868 \\
\hline & $(6.03)$ & $(-5.03)$ & $(11.24)$ & $(-0.67)$ & & & \\
\hline \multirow[t]{2}{*}{ FF5 } & $0.314^{* * *}$ & $-0.255^{* * *}$ & $0.079^{* * *}$ & -0.004 & 0.008 & 0.039 & 0.862 \\
\hline & $(4.15)$ & $(-3.84)$ & $(10.44)$ & $(-0.72)$ & $(0.14)$ & $(1.18)$ & \\
\hline \multicolumn{8}{|c|}{ Panel B: Sub-period 1 (Bull), Dec 1, 2006 to Oct 31, 2007, T=221 } \\
\hline \multirow[t]{2}{*}{ CAPM } & $0.359^{* *}$ & 0.170 & & & & & 0.046 \\
\hline & $(2.72)$ & $(1.37)$ & & & & & \\
\hline \multirow[t]{2}{*}{ FF3 } & $0.418^{* *}$ & 0.131 & -0.028 & $0.042^{* *}$ & & & 0.117 \\
\hline & $(2.34)$ & $(0.73)$ & $(-1.30)$ & $(2.22)$ & & & \\
\hline \multirow[t]{2}{*}{ FF5 } & 0.214 & $0.296^{* *}$ & -0.024 & 0.031 & 0.034 & $0.169 * * *$ & 0.309 \\
\hline & $(1.71)$ & $(2.47)$ & $(-1.26)$ & $(1.47)$ & $(0.70)$ & $(3.59)$ & \\
\hline \multicolumn{8}{|c|}{ Panel C: Sub-period 2 (Bear), Nov 1, 2007 to Nov 4, 2008, T=247 } \\
\hline \multirow[t]{2}{*}{ CAPM } & -0.393 & 0.006 & & & & & -0.043 \\
\hline & $(-0.99)$ & $(0.02)$ & & & & & \\
\hline \multirow[t]{2}{*}{ FF3 } & 0.190 & $-0.662^{* * *}$ & $0.110^{* * *}$ & $0.034^{* * *}$ & & & 0.805 \\
\hline & $(1.68)$ & $(-6.07)$ & $(9.36)$ & $(2.97)$ & & & \\
\hline \multirow[t]{2}{*}{ FF5 } & 0.192 & $-0.657 * * *$ & $0.110^{* * *}$ & $0.033^{* * *}$ & -0.110 & $0.112^{*}$ & 0.786 \\
\hline & $(1.63)$ & $(-5.43)$ & $(8.29)$ & $(3.12)$ & $(-1.70)$ & $(2.05)$ & \\
\hline \multicolumn{8}{|c|}{ Panel D: Sub-period 3 (Consolidation), Nov 5, 2008 to Oct 27, 2014, T=1450 } \\
\hline \multirow[t]{2}{*}{ CAPM } & $-0.326^{*}$ & $0.390 * *$ & & & & & 0.258 \\
\hline & $(-1.98)$ & $(2.59)$ & & & & & \\
\hline \multirow[t]{2}{*}{ FF3 } & $0.191^{* * *}$ & $-0.141^{* *}$ & $0.083^{* * *}$ & $-0.021 * * *$ & & & 0.921 \\
\hline & $(3.69)$ & $(-2.80)$ & $(14.35)$ & $(-3.81)$ & & & \\
\hline \multirow[t]{2}{*}{ FF5 } & $0.172^{* *}$ & $-0.124^{* *}$ & $0.084^{* * *}$ & $-0.021 * * *$ & 0.016 & 0.018 & 0.923 \\
\hline & $(2.80)$ & $(-2.10)$ & $(16.38)$ & $(-4.93)$ & $(0.65)$ & $(0.89)$ & \\
\hline \multicolumn{8}{|c|}{ Panel E: Sub-period 4 (Bull), Oct 28, 2014 to Jun 12, 2015, T=155 } \\
\hline \multirow[t]{2}{*}{ CAPM } & $0.986^{* * *}$ & $-0.365^{* * *}$ & & & & & 0.190 \\
\hline & $(8.02)$ & $(-2.92)$ & & & & & \\
\hline \multirow[t]{2}{*}{ FF3 } & $0.66^{* *}$ & -0.070 & $0.104^{* * *}$ & -0.027 & & & 0.367 \\
\hline & $(2.31)$ & $(-0.26)$ & $(3.34)$ & $(-0.86)$ & & & \\
\hline \multirow[t]{2}{*}{ FF5 } & $0.507 * *$ & -0.018 & $0.109^{* * *}$ & -0.045 & -0.159 & $0.093^{*}$ & 0.387 \\
\hline & $(2.15)$ & $(-0.08)$ & $(3.11)$ & $(-1.47)$ & $(-1.64)$ & $(1.84)$ & \\
\hline Panel $F$ & Sub-period & (Bear), Jur & 13, 2015 to & $n 28,2016$, & $=155$ & & \\
\hline CAPM & $-0.663^{* * *}$ & $0.225 *$ & & & & & 0.043 \\
\hline & $(-4.53)$ & $(1.81)$ & & & & & \\
\hline FF3 & $0.645^{* * *}$ & $-1.018 * * *$ & $0.085^{* * *}$ & -0.038 & & & 0.550 \\
\hline & $(2.89)$ & $(-4.86)$ & $(4.73)$ & $(-1.30)$ & & & \\
\hline FF5 & $0.736^{*}$ & $-1.093^{* * *}$ & $0.084 * * *$ & -0.032 & 0.006 & -0.005 & 0.511 \\
\hline & $(2.04)$ & $(-3.14)$ & $(4.59)$ & $(-1.16)$ & $(0.17)$ & $(-0.12)$ & \\
\hline Panel $C$ & Sub-period & (Consolida & n), Jan 29, & 016 to Nov & $2016, T$ & 203 & \\
\hline CAPM & -0.088 & $0.203^{* * *}$ & & & & & 0.256 \\
\hline & $(-1.12)$ & $(3.00)$ & & & & & \\
\hline FF3 & $0.305^{* * *}$ & $-0.179^{* *}$ & $0.096 * * *$ & $0.016^{* * *}$ & & & 0.845 \\
\hline & $(3.71)$ & $(-2.34)$ & (13.40) & $(2.97)$ & & & \\
\hline FF5 & 0.039 & 0.082 & $0.096^{* * *}$ & $0.018^{* *}$ & $0.069^{* *}$ & 0.013 & 0.882 \\
\hline & $(0.30)$ & $(0.66)$ & $(16.79)$ & $(2.47)$ & $(2.20)$ & $(0.76)$ & \\
\hline
\end{tabular}

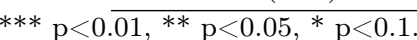

This table reports the results of cross-sectional regressions for the three models within the full sample period and the six sub-periods separated based on market trends. The cross-sectional regressions are based on the second stage of the Fama-MacBeth approach. 
Table 8: Instability test results for the CAPM

\begin{tabular}{|c|c|c|c|c|c|c|c|c|c|c|}
\hline \multirow{2}{*}{$\begin{array}{l}\text { Size } \\
B / M\end{array}$} & \multicolumn{5}{|c|}{ Small } & \multicolumn{5}{|c|}{2} \\
\hline & Low & 2 & 3 & 4 & High & Low & 2 & 3 & 4 & High \\
\hline Joint & $9.130^{* * *}$ & $9.130^{* * *}$ & $8.733^{* * *}$ & $8.906^{* * *}$ & $6.032^{* * *}$ & $7.247^{* * *}$ & $8.023^{* * *}$ & $4.994^{* * *}$ & $4.831^{* * *}$ & $4.674^{* * *}$ \\
\hline Variance & $1.938^{* * *}$ & $1.938^{* * *}$ & $2.904^{* * *}$ & $2.395^{* * *}$ & $1.896^{* * *}$ & $1.859^{* * *}$ & $2.612^{* * *}$ & $1.601^{* * *}$ & $1.565^{* * *}$ & $1.946^{* * *}$ \\
\hline Intercept & 0.168 & 0.168 & 0.315 & 0.279 & 0.119 & 0.075 & 0.098 & 0.087 & 0.054 & 0.047 \\
\hline MKT & $6.511^{* * *}$ & $6.511^{* * *}$ & $4.636^{* * *}$ & $5.434^{* * *}$ & $3.613^{* * *}$ & $4.973^{* * *}$ & $4.919^{* * *}$ & $2.966^{* * *}$ & $3.001^{* * *}$ & $2.405^{* * *}$ \\
\hline Size & \multicolumn{5}{|c|}{3} & \multicolumn{5}{|c|}{4} \\
\hline$B / M$ & Low & 2 & 3 & 4 & High & Low & 2 & 3 & 4 & High \\
\hline Joint & $13.053^{* * *}$ & $8.501^{* * *}$ & $6.042^{* * *}$ & $5.110^{* * *}$ & $5.408^{* * *}$ & $13.513^{* * *}$ & $6.965^{* * *}$ & $3.896^{* * *}$ & $4.862^{* * *}$ & $4.377^{* * *}$ \\
\hline Variance & $3.319^{* * *}$ & $3.322^{* * *}$ & $1.682^{* * *}$ & $1.632^{* * *}$ & $2.027 * * *$ & $5.277^{* * *}$ & $2.463^{* * *}$ & $1.736^{* * *}$ & $1.431^{* * *}$ & $1.499 * * *$ \\
\hline Intercept & 0.067 & 0.122 & 0.046 & 0.048 & 0.098 & 0.113 & 0.05 & 0.114 & 0.049 & 0.074 \\
\hline MKT & $9.958^{* * *}$ & $4.749^{* * *}$ & $4.279^{* * *}$ & $3.281^{* * *}$ & $2.674^{* * *}$ & $8.087^{* * *}$ & $4.550 * * *$ & $2.126^{* * *}$ & $2.778^{* * *}$ & $2.432^{* * *}$ \\
\hline Size & \multicolumn{5}{|c|}{ Big } & \multirow{2}{*}{\multicolumn{5}{|c|}{$\frac{\text { No. of Sig. }}{1^{\sim 5 \%} \quad 5^{\sim} 10 \%}$}} \\
\hline$B / M$ & Low & 2 & 3 & 4 & High & & & & & \\
\hline Joint & $9.411^{* * *}$ & $2.513^{* * *}$ & $3.970^{* * *}$ & $4.464^{* * *}$ & $6.482^{* * *}$ & 25 & 0 & 0 & 25 & \\
\hline Variance & $3.998^{* * *}$ & $0.978 * * *$ & $3.202^{* * *}$ & $2.220 * * *$ & $3.889^{* * *}$ & 25 & 0 & 0 & 25 & \\
\hline Intercept & 0.161 & 0.154 & $0.415^{*}$ & 0.138 & 0.025 & 0 & 0 & 1 & 1 & \\
\hline MKT & $6.208^{* * *}$ & $1.501^{* * *}$ & $0.666^{* *}$ & $2.231^{* * *}$ & $2.237^{* * * *}$ & 24 & 1 & 0 & 25 & \\
\hline
\end{tabular}

$* * * \mathrm{p}<0.01,{ }^{* *} \mathrm{p}<0.05, * \mathrm{p}<0.1$.
This table reports the Hansen's (1992) statistics for instability tests on the joint and individual parameters; the null hypotheses is that all parameters are jointly constant, and that individual parameters (coefficients and variance of the errors) are also constant. The tests are robust to heteroskedasticity. The null distribution is non-standard and depends upon the number of parameters tested for instability. The critical values are computed by simulation in Nyblom (1989) and Hansen (1992). The panel of "No. of Sig." summarises the number of significant instability statistics across the 25 portfolios at the corresponding significant levels.

critical value.

Hansen's (1992) instability tests are robust to heteroskedasticity. The null distribution is nonstandard and depends upon the number of parameters tested for stability. Nyblom (1989) and Hansen (1992) provide the critical values computed by simulation. (For the relevant critical values extracted from Hansen (1992).) Hansen's $L_{1}$ test for the constancy of intercept is analogous to the CUSUM test. Hansen's $L_{k+1}$ test for the constancy of variance is analogous to CUSUMSQ test. Hansen's $L_{c}$ test for the constancy of all parameters is similar to Nyblom's test. ${ }^{12}$

The values of Hansen's (1992) statistics for the joint and individual instability tests for the CAPM, the FF3 and the FF5 over the full sample are reported in Tables 8, 9, and 10, respectively. For each instability test across the 25 portfolios, the numbers of significant statistics are summarised under "No. of Sig.". According to the joint instability tests, all three models are non-constant at the $1 \%$ significant level over time for all the 25 portfolios.

For the tests on each individual coefficient, we find that the intercepts of the three models are generally insignificant. Only one out of 25 intercepts of the CAPM is significant at the $10 \%$ level, while the numbers of significant intercepts for the FF3 and the FF5 are only slightly greater.

As for the CAPM, both the model's variance and market beta are non-constant across the 25 portfolios over time. Although adding the additional size and value factors does not decrease the level of instability of the FF3 model as a whole, it reduces the number of significant market betas from 25 (24 at the $1 \%$ level and 1 at the 1 5\% level) for the CAPM to 22 (11 at the $1 \%$ level, 6 at the $1 \sim 5 \%$ level, and 5 at the $5 \sim 10 \%$ level) for the FF5. In addition, 20 size factor loadings present significant instability at the $10 \%$ level, while the coefficients related to the value factor are all non-constant. Further, adding the investment and profitability factors decreases the number of significant market betas to only 14, but other parameters are not influenced. The RMW loadings are highly unstable, while the CMA loadings not, with 18 CMA loadings being significant.

As before, we also conduct the instability test within each of the six sub-periods. For brevity, we

\footnotetext{
${ }^{12}$ Note that the distribution of the test statistic is different if the data are nonstationary (e.g., unit root, deterministic trend). See Hansen (2002) for more details. Our data for the 25 portfolio returns and the five factor premiums do not suffer from the problem of nonstationary.
} 
Table 9: Instability test results for the FF3

\begin{tabular}{|c|c|c|c|c|c|c|c|c|c|c|}
\hline \multirow{2}{*}{$\begin{array}{l}\text { Size } \\
B / M\end{array}$} & \multicolumn{5}{|c|}{ Small } & \multicolumn{5}{|c|}{2} \\
\hline & Low & 2 & 3 & 4 & High & Low & 2 & 3 & 4 & High \\
\hline Joint & $7.718^{* * *}$ & $6.468^{* * *}$ & $9.701^{* * *}$ & $13.231^{* * *}$ & $13.708^{* * *}$ & $11.536^{* * *}$ & $15.567^{* * *}$ & $10.860^{* * *}$ & $8.425^{* * *}$ & $5.523^{* * *}$ \\
\hline Variance & $4.514^{* * *}$ & $2.488^{* * *}$ & $2.283^{* * *}$ & $1.951^{* * *}$ & $5.586^{* * *}$ & $9.332^{* * *}$ & $7.295^{* * *}$ & $6.152^{* * *}$ & $3.526^{* * *}$ & $1.978^{* * *}$ \\
\hline Intercept & 0.143 & 0.07 & 0.231 & 0.158 & 0.034 & 0.055 & 0.053 & 0.116 & $0.436^{*}$ & $0.452^{*}$ \\
\hline MKT & $2.094^{* * *}$ & $0.587^{* *}$ & $0.403^{*}$ & $1.361^{* * *}$ & $0.680^{* *}$ & 0.332 & $0.913^{* * *}$ & $0.466^{*}$ & $0.395^{*}$ & 0.29 \\
\hline SMB & $0.546^{* *}$ & $1.120^{* * *}$ & $1.964^{* * *}$ & $2.099^{* * *}$ & $1.174^{* * *}$ & $0.478^{* *}$ & $1.479^{* * *}$ & 0.276 & $1.234^{* * *}$ & 0.301 \\
\hline HML & $0.573^{* *}$ & $2.589^{* * *}$ & $5.558 * * *$ & $7.717^{* * *}$ & $5.358^{* * *}$ & $1.173^{* * *}$ & $6.411^{* * *}$ & $3.150 * * *$ & $3.657^{* * *}$ & $1.258^{* * *}$ \\
\hline Size & \multicolumn{5}{|c|}{3} & \multicolumn{5}{|c|}{4} \\
\hline$B / M$ & Low & 2 & 3 & 4 & High & Low & 2 & 3 & 4 & High \\
\hline Joint & $19.702^{* * *}$ & $16.512^{* * *}$ & $9.444^{* * *}$ & $6.082^{* * *}$ & $6.027^{* * *}$ & $16.741^{* * *}$ & $16.196^{* * *}$ & $8.802^{* * *}$ & $5.623^{* * *}$ & $3.930^{* * *}$ \\
\hline Variance & $9.228^{* * *}$ & $6.578^{* * *}$ & $3.414^{* * *}$ & $2.077^{* * *}$ & $0.904^{* * *}$ & $5.255^{* * *}$ & $8.131^{* * *}$ & $3.976^{* * *}$ & $2.202^{* * *}$ & $0.927^{* * *}$ \\
\hline Intercept & 0.348 & 0.066 & $0.379^{*}$ & 0.302 & $0.591^{* *}$ & 0.217 & 0.242 & $0.558^{* *}$ & 0.318 & 0.032 \\
\hline MKT & $5.008^{* * *}$ & $0.514^{* *}$ & $0.597^{* *}$ & $0.428^{*}$ & $0.930^{* * *}$ & $1.955^{* * *}$ & $0.496^{* *}$ & 0.283 & $0.382^{*}$ & $1.913^{* * *}$ \\
\hline SMB & $1.530^{* * *}$ & $1.514^{* * *}$ & $0.480^{* *}$ & 0.306 & $0.901^{* * *}$ & $2.164^{* * *}$ & 0.327 & $0.402^{*}$ & 0.158 & $1.197 * * *$ \\
\hline HML & $3.657^{* * *}$ & $7.423^{* * *}$ & $3.196^{* * *}$ & $2.076^{* * *}$ & $2.470^{* * *}$ & $8.054^{* * *}$ & $5.715^{* * *}$ & $2.541^{* * *}$ & $0.574^{* *}$ & $0.775^{* * *}$ \\
\hline Size & \multicolumn{5}{|c|}{ Big } & \multicolumn{5}{|c|}{ No. of Sig. } \\
\hline$B / M$ & Low & 2 & 3 & 4 & High & $<1 \%$ & $1 \sim 5 \%$ & $5 \sim 10 \%$ & Total & \\
\hline Joint & $9.155^{* * *}$ & $5.305^{* * *}$ & $9.048^{* * *}$ & $9.779^{* * *}$ & $15.489^{* * *}$ & 25 & 0 & 0 & 25 & \\
\hline Variance & $0.566^{* *}$ & $2.135^{* * *}$ & $3.511^{* * *}$ & $2.254^{* * *}$ & $9.967 * * *$ & 24 & 1 & 0 & 25 & \\
\hline Intercept & 0.196 & 0.171 & $0.400^{*}$ & 0.128 & 0.058 & 0 & 2 & 4 & 6 & \\
\hline MKT & $1.425^{* * *}$ & $1.727^{* * *}$ & $0.700^{* *}$ & $3.894^{* * *}$ & $1.570 * * *$ & 11 & 6 & 5 & 22 & \\
\hline SMB & $1.416^{* * *}$ & $0.968^{* * *}$ & $0.728^{* *}$ & $1.465^{* * *}$ & $4.644^{* * *}$ & 15 & 4 & 1 & 20 & \\
\hline HML & $5.605^{* * *}$ & $0.796^{* * *}$ & $2.544^{* * *}$ & $3.416^{* * *}$ & $3.877^{* * *}$ & 23 & 2 & 0 & 25 & \\
\hline
\end{tabular}

This table reports the Hansen's (1992) instability tests on both joint and individual parameters; the null hypotheses that all parameters are jointly constant and that individual parameters (coefficients and variance of the errors) are constant. The tests are robust to heteroskedasticity. The null distribution is non-standard and depends upon the number of parameters tested for instability. The critical values are computed by simulation in Nyblom (1989) and Hansen (1992). The panel of "No. of Sig." summarises the number of significant instability statistics across the 25 portfolios at the corresponding significance levels.

Table 10: Instability test results for the FF5

\begin{tabular}{|c|c|c|c|c|c|c|c|c|c|c|}
\hline \multirow{2}{*}{$\begin{array}{c}\text { Size } \\
B / M\end{array}$} & \multicolumn{5}{|c|}{ Small } & \multicolumn{5}{|c|}{2} \\
\hline & Low & 2 & 3 & 4 & High & Low & 2 & 3 & 4 & High \\
\hline Joint & $8.354^{* * *}$ & $11.635^{* * *}$ & $13.249^{* * *}$ & $14.900 * * *$ & $16.622^{* * *}$ & $19.373^{* * *}$ & $18.451^{* * *}$ & $17.151^{* * *}$ & $11.961^{* * *}$ & $7.236^{* * *}$ \\
\hline Variance & $4.998^{* * *}$ & $3.153^{* * *}$ & $2.014^{* * *}$ & $1.808^{* * *}$ & $5.425^{* * *}$ & $12.389^{* * *}$ & $7.555^{* * *}$ & $6.984^{* * *}$ & $3.823^{* * *}$ & $1.805^{* * *}$ \\
\hline Intercept & 0.166 & 0.066 & 0.284 & 0.202 & 0.025 & 0.028 & 0.028 & 0.078 & 0.347 & $0.358^{*}$ \\
\hline MKT & $0.431^{*}$ & 0.241 & 0.094 & $0.711^{* *}$ & 0.327 & 0.261 & $0.491 * *$ & $1.051^{* * *}$ & 0.353 & 0.236 \\
\hline SMB & $0.514^{* *}$ & $1.545^{* * *}$ & $2.378^{* * *}$ & $2.388^{* * *}$ & $1.425^{* * *}$ & $0.909^{* * *}$ & $2.021 * * *$ & $0.463^{*}$ & $1.702^{* * *}$ & 0.329 \\
\hline HML & $2.071 * * *$ & $3.845^{* * *}$ & $6.456^{* * *}$ & $8.065^{* * *}$ & $6.128^{* * *}$ & $3.455^{* * *}$ & $8.661^{* * *}$ & $5.241^{* * *}$ & $4.793^{* * *}$ & $2.225 * * *$ \\
\hline RMW & $0.537^{* *}$ & $3.563^{* * *}$ & $3.512^{* * *}$ & $3.265^{* * *}$ & $1.740^{* * *}$ & $3.090^{* * *}$ & $2.882^{* * *}$ & $2.087 * * *$ & $2.471^{* * *}$ & $1.220^{* * *}$ \\
\hline CMA & $0.368^{*}$ & $0.796^{* * *}$ & $0.355^{*}$ & $0.624^{* *}$ & $0.693^{* *}$ & $2.544^{* * *}$ & 0.204 & $0.548^{* *}$ & 0.309 & $0.490^{* *}$ \\
\hline Size & \multicolumn{5}{|c|}{3} & \multicolumn{5}{|c|}{4} \\
\hline$B / M$ & Low & 2 & 3 & 4 & High & Low & 2 & 3 & 4 & High \\
\hline Joint & $24.506^{* * *}$ & $21.356^{* * *}$ & $14.145^{* * *}$ & $9.274^{* * *}$ & $6.328^{* * *}$ & $22.098^{* * *}$ & $18.737^{* * *}$ & $13.382^{* * *}$ & $7.818^{* * *}$ & $6.168^{* * *}$ \\
\hline Variance & $12.039^{* * *}$ & $6.909^{* * *}$ & $3.956^{* * *}$ & $2.327 * * *$ & $0.869^{* * *}$ & $5.983^{* * *}$ & $8.247 * * *$ & $4.315^{* * *}$ & $2.517 * * *$ & $0.740^{* *}$ \\
\hline Intercept & 0.275 & 0.082 & 0.313 & 0.226 & $0.490 * *$ & 0.223 & 0.182 & $0.451^{*}$ & 0.233 & 0.086 \\
\hline MKT & $2.721 * * *$ & $0.401^{*}$ & 0.318 & 0.252 & 0.153 & $0.679^{* *}$ & $0.372^{*}$ & $1.250 * * *$ & 0.179 & 0.272 \\
\hline SMB & $2.159^{* * *}$ & $1.947^{* * *}$ & $0.816^{* * *}$ & $0.397^{*}$ & $0.970 * * *$ & $2.753^{* * *}$ & $0.422^{*}$ & $0.694^{* *}$ & 0.127 & $1.887 * * *$ \\
\hline HML & $4.899^{* * *}$ & $9.049^{* * *}$ & $5.321^{* * *}$ & $2.978^{* * *}$ & $2.791^{* * *}$ & $9.166^{* * *}$ & $6.116^{* * *}$ & $3.617^{* * *}$ & $1.174^{* * *}$ & $1.643^{* * *}$ \\
\hline RMW & $4.844^{* * *}$ & $3.252^{* * *}$ & $2.291^{* * *} *$ & $1.155^{* * *}$ & $1.438 * * *$ & $4.505^{* * *}$ & $0.796^{* * *}$ & $1.461^{* * *}$ & $0.495^{* *}$ & $2.571^{* * *}$ \\
\hline CMA & $1.197 * * *$ & $0.397^{*}$ & $0.540^{* *}$ & 0.201 & $0.616^{* *}$ & 0.337 & $0.946^{* * *}$ & 0.267 & 0.183 & $2.934^{* * *}$ \\
\hline Size & \multicolumn{5}{|c|}{ Big } & \multicolumn{5}{|c|}{ No. of Sig. } \\
\hline$B / M$ & Low & 2 & 3 & 4 & High & $<1 \%$ & $1 \sim 5 \%$ & $5 \sim 10 \%$ & Total & \\
\hline Joint & $10.220^{* * *}$ & $8.532^{* * *}$ & $17.398^{* * *}$ & $14.650^{* * *}$ & $19.052^{* * *}$ & 25 & 0 & 0 & 25 & \\
\hline Variance & $0.542^{* *}$ & $1.650^{* * *}$ & $4.758^{* * *}$ & $2.427 * * *$ & $10.234^{* * *}$ & 23 & 2 & 0 & 25 & \\
\hline Intercept & 0.173 & 0.136 & 0.287 & 0.077 & 0.096 & 0 & 1 & 2 & 3 & \\
\hline MKT & $0.945^{* * *}$ & $2.234^{* * *}$ & $1.985^{* * *}$ & $1.769^{* * *}$ & $0.848^{* * *}$ & 8 & 3 & 3 & 14 & \\
\hline SMB & $1.518^{* * *}$ & $1.167^{* * * *}$ & $0.763^{* * *}$ & $1.934^{* * *}$ & $6.169^{* * *}$ & 18 & 2 & 3 & 23 & \\
\hline HML & $5.931 * * *$ & $1.265^{* * *}$ & $4.051^{* * *}$ & $5.365 * * *$ & $6.504^{* * *}$ & 25 & 0 & 0 & 25 & \\
\hline RMW & $1.883^{* * *}$ & $1.330 * * *$ & $1.798 * * *$ & $4.404^{* * *}$ & $6.421^{* * *}$ & 23 & 2 & 0 & 25 & \\
\hline CMA & $0.626^{* *}$ & 0.139 & $0.565^{* *}$ & $1.741^{* * *}$ & $1.766^{* * *}$ & 7 & 8 & 3 & 18 & \\
\hline
\end{tabular}

This table reports Hansen's (1992) for instability tests for joint and individual parameters; the null hypotheses is that all parameters are jointly constant and that individual parameters (coefficients and variance of the errors) are constant. The tests are robust to heteroskedasticity. The null distribution is non-standard and depends upon the number of parameters tested for instability. The critical values are computed by simulation in Nyblom (1989) and Hansen (1992). The panel of "No. of Sig." summarises the number of significant instability statistics across the 25 portfolios at the corresponding significant levels. 
report the summary for the significant statistics across the 25 portfolios in Table 11. We first look at the three sub-periods in the second round of the boom-crash, i.e., Panels D, E, and F, because it is easier to interpret. Notice that the sample sizes are similar within these three sub-periods. We can see that the models are less non-constant during consolidation because the numbers of significant instability statistics for joint and each individual tests are generally smaller than in the bull and the bear. Adding more factors decreases the degree of model instability. Then, looking at the first round of boom-crash, i.e., Panels A, B, and C, the numbers of significant statistics are much smaller in Panels A and B than in Panel C. So, at first sight, one may conclude that according to the instability statistics, the models are highly unstable across the 25 portfolios in the third sub-period of consolidation. This is not exactly the case, however. We want to emphasise that the number of observations, $T$, in the third sub-period (Panel C) is 1450, much greater than those in the other five sub-periods. In fact, the instability statistics are influenced by the number of observations. Intuitively, when the time interval enlarges, or the time period becomes longer, there is a higher possibility of introducing the breaking points for the models. Thus, we further divided the third sub-period of consolidation into six intervals with each containing around 200 to 250 observations, and compute the corresponding Hansen's instability statistics. Although not reported in this paper for the sake of brevity, we find that the magnitude of these statistics is much smaller than those reported in Panel C; and more importantly, that the numbers of significant statistics also decrease and become less than those in the first and second panels. Thus, combined with the evidence from Panels D, E and F, we conclude that the models tend to be more unstable in the trending markets of bull and bear. To further support our argument, we will conduct a visual examination based on recursive regressions in the following sub-section.

\subsection{Recursive regression}

Hansen's (1992) instability tests are informative about the type of structural change in models, but not about the date of structural change. Thus, it is also helpful to provide a visual description of the changes in the model parameters. Hence, we also plot the graphs of recursive estimations to look at the structural changes within different periods. Because the FF5 model can better explain the equity returns and is less unstable than the CAPM and the FF3 over our sample period, in the following paragraphs, we only focus on the graphs for the FF5. According to the joint instability test in Table 10, the FF5 presents the most significant instability for the middle size and lowest $\mathrm{B} / \mathrm{M}$ portfolio (S3BM1), and the least significant instability for the second biggest size and the highest B/M portfolio (S4BM5). To save space, we only present the graphs of recursive regressions for these two typical portfolios for the purpose of interpretation. ${ }^{13}$

Figure 3 presents the graphs of recursive estimations for the Portfolio S3BM1. The green shaded areas represent the bull markets, the grey shaded areas represent the bear markets, and the unshaded areas represent the consolidation markets. From Table 10, the majority of the individual coefficients are non-constant over the full sample period. The graphs of the coefficients related to the five factors further show that the coefficients fluctuate more during the green and grey shaded sub-periods. Furthermore, the graph of the 1-step residuals with $\pm 2 \hat{\sigma}_{t}$ plotted on either side of zero shows that the major breaking points fall into the green and grey shaded sub-periods, and that the two $\pm 2 \hat{\sigma}_{t}$ lines also enlarge within these sub-periods and narrow after the crashes. ${ }^{14}$ The 1 -step Chow tests also reflect the parameters' instability. The graph of "1up CHOWs" shows that the dates that the values of the Chow $F$-test exceed its $1 \%$ critical value are mostly within the shaded

\footnotetext{
${ }^{13}$ The graphs of the recursive regressions for the rest 23 portfolios present similar patterns to those shown in this paper and are omitted for the sake of brevity. They are readily available upon request, however.

${ }^{14}$ Note that the residuals outside of the error bars are either outliers or are associated with changes in $\hat{\sigma}_{t}$.
} 


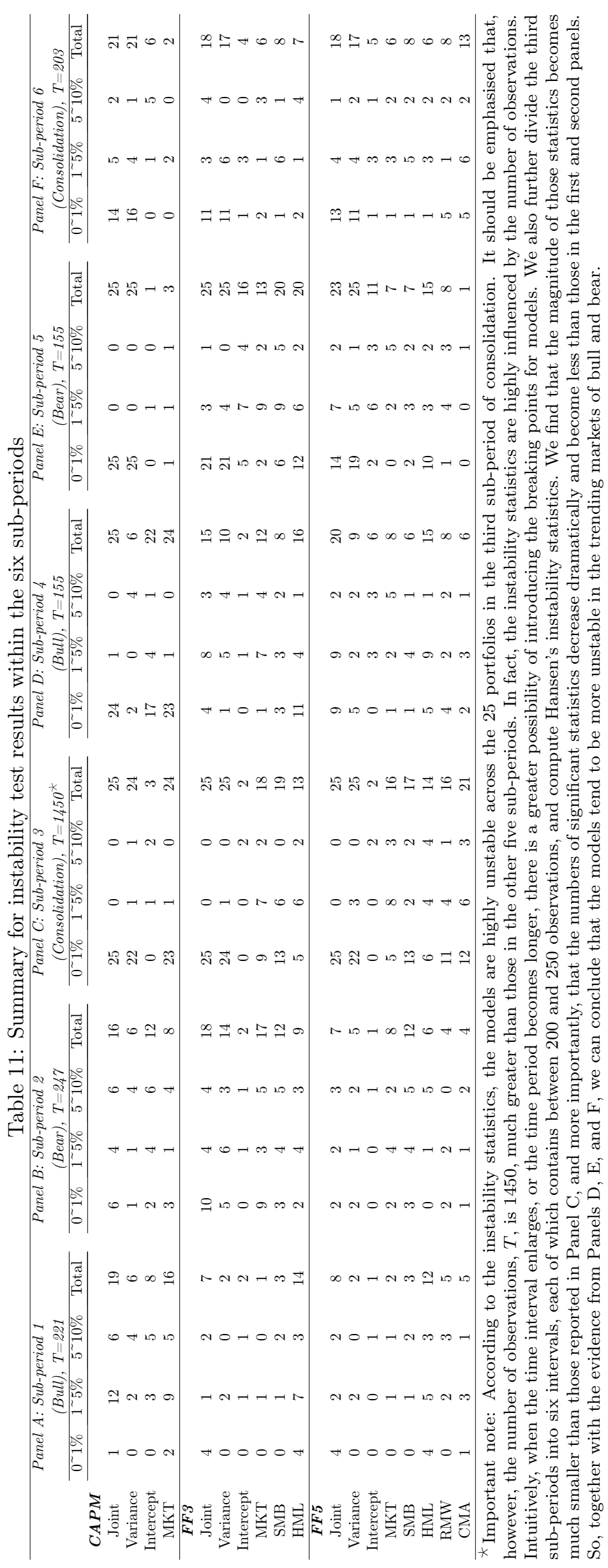


periods. Compared between the bull and bear markets, it seems that the degree of instability is higher in the grey shaded periods when the Chinese market is in the crash.

Figure 4 shows the graphs for the Portfolio S4BM5. The graphs present similar non-constant patterns of the coefficients as in Figure 3. Although the evidence in the graphs of 1-step residuals and Chow tests is not as obvious as that in the previous figure, the graphs show major breaking points of residuals gathering in the shaded periods, especially the second bear market. More importantly, the two $\pm 2 \hat{\sigma}_{t}$ lines enlarge within the shaded periods and narrow after the two crashed markets. Moreover, the degree of instability is also higher in the crash than in the boom.

Generally speaking, the graphs, including those not presented in this paper, suggest that the FF5 is largely non-constant over time. Furthermore, the FF5 appears to be more unstable in the trending markets, and the instability tends to be even higher in the crash.

Because recursive regression increases the length of the window by 1 as it moves forward in time with a new observation added into the regression, the coefficient estimates will be smoothed as the window increases. For robust tests on the above findings, we also run inverse recursive regressions from the last day backward to the first day within the full sample period. We find the same patterns of instability: the coefficients present a higher level of non-constancy, and the errors of residuals tend to enlarge in the trending markets, particularly in the crashes.

In sum, the instability tests on the FF5 based on Hansen (1992), as well as the graphs of recursive regressions, provide a sketch for the time-series changes in the model's coefficients and the model per se. We conclude that the FF5 tends to present higher instability in the crash periods.

\section{Conclusion}

We investigated the performance of the three nested models, i.e., the CAPM, the FF3 and FF5, in the Chinese stock market during the period December 1, 2006 to November 30, 2016. This period covers two historical boom-crash turnings, December 1, 2006 to November 4, 2008, and October 28, 2014 to January 28, 2016. For the rest of the period, the market consolidates at a relatively low level. Thus, our sample provides an opportunity to examine the factor models under different market trends. Unlike most of the existing studies, we split our sample into six sub-periods, each of which represents one type of three different market trends: bull, bear, and consolidation. After an extensive literature survey, we realised that this paper is the first comprehensive study to examine the factor models for different market trends.

Our empirical methods consisted of time-series analysis, cross-sectional analysis and instability tests. According to the time-series regressions, the results over the full sample period do not present any surprises about the performance of the three nested models. When we examine the models within the six sub-periods, however, some interesting findings occur. First, the three models perform best in the bear markets in terms of the time-series adjusted $R^{2}$, i.e., they can best explain the time-series variations in the excess returns on the 25 size-B/M sorted portfolios when the market crashes. This should be attributed to the higher degree of stock price synchronicity in the crash.

On the other hand, the factor models have more difficulty explaining the cross-sectional variations in the portfolio returns in the trending markets, including the bull and bear markets, based on the second stage of the Fama-MacBeth approach. The cross-sectional average adjusted $R^{2}$ for all three models is smaller in the booms and crashes than in the consolidations, although adding additional factors can remarkably increase the cross-sectional average adjusted $R^{2}$.

The conclusions from the time-series and cross-sectional analyses ostensibly conflict with each other in terms of that a larger time-series adjusted $R^{2}$ is matched to a smaller cross-sectional 

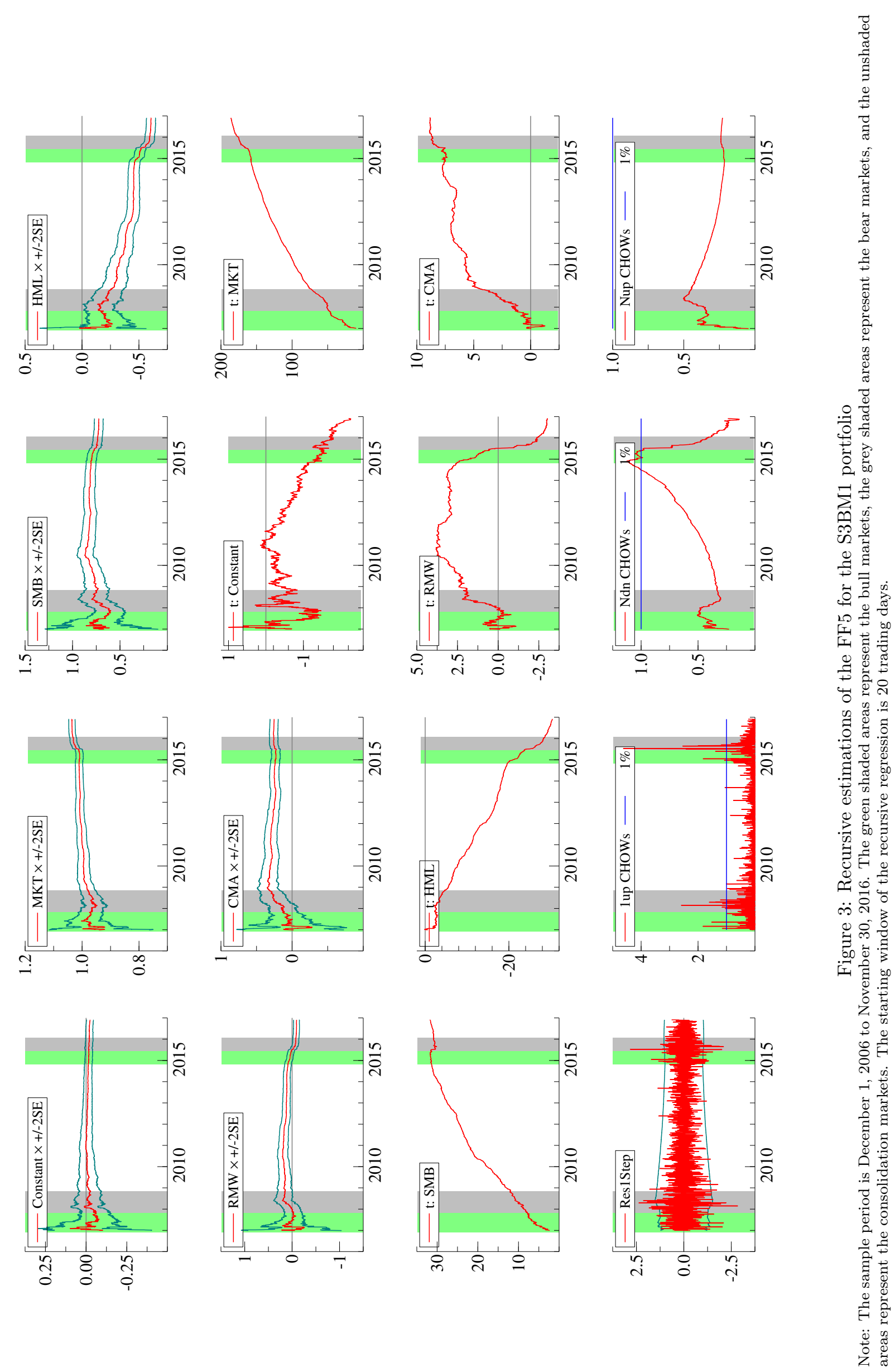

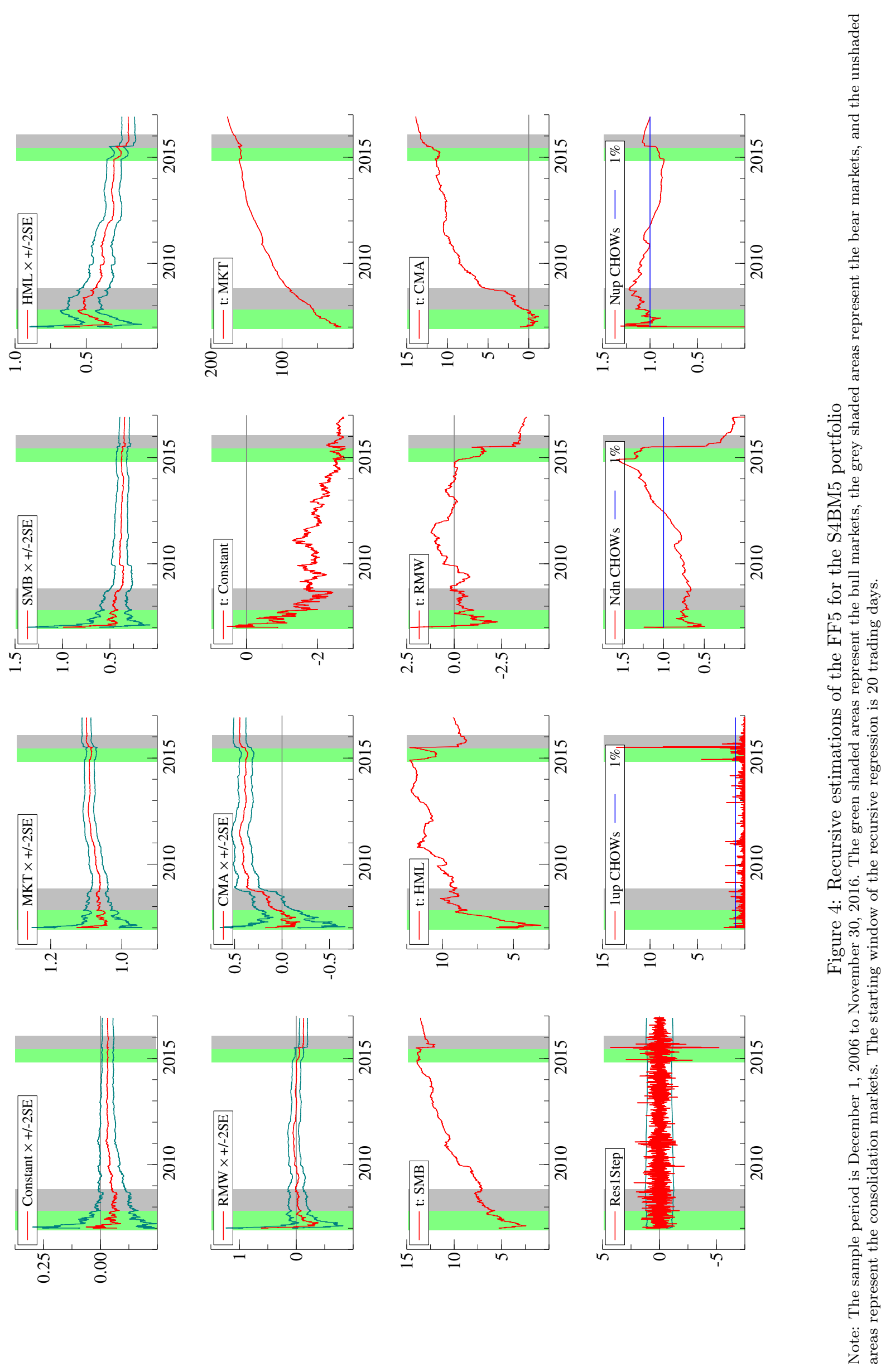
adjusted $R^{2}$ in the crashes. We provide a possible explanation by conducting instability tests for the three models. According to Hansen's instability statistics within the six sub-periods, the models and their parameters tend to be more unstable in the trending markets, especially in the crash. This finding is further supported by the graphs drawing the time-series changes in the model estimations from recursive regressions. We argue that the higher instability of the factor models in the trending markets contributes to the weaker performance of the models in explaining the cross-sectional variations in portfolio returns in the trending markets. 


\section{References}

Barillas, F., Shanken, J., 2016. Which Alpha? The Review of Financial Studies 30, 1316-1338.

Barndorff-Nielsen, O.E., Shephard, N., 2010. Volatility. American Cancer Society.

Breeden, D.T., 1979. An intertemporal asset pricing model with stochastic consumption and investment opportunities. Journal of Financial Economics 7, 265-296.

Cakici, N., Chan, K., Topyan, K., 2015. Cross-sectional stock return predictability in china. The European Journal of Finance, 1-25.

Carhart, M.M., 1997. On persistence in mutual fund performance. The Journal of Finance 52, $57-82$.

Carpenter, J.N., Lu, F., Whitelaw, R.F., 2015. The real value of China's stock market. Technical Report. National Bureau of Economic Research.

Chen, C., Hu, X., Shao, Y., Wang, J., 2015. Fama-French in China: Size and value factors in Chinese stock returns. University of Hong Kong Working Paper .

Chen, X., Kim, K.A., Yao, T., Yu, T., 2010. On the predictability of Chinese stock returns. Pacific-Basin Finance Journal 18, 403-425.

Dimson, E., Marsh, P., 1998. Murphy's law and market anomalies. Available at SSRN 135681 .

Ding, Z., Granger, C., 1996. Modeling volatility persistence of speculative returns: A new approach. Journal of Econometrics 73, 185-215.

Ding, Z., Granger, C.W.J., Engle, R.F., 1993. A long memory property of stock market returns and a new model. Journal of Empirical Finance 1, 83-106.

Faff, R.W., 2004. A simple test of the Fama and French model using daily data: Australian evidence. Applied Financial Economics 14, 83-92.

Fama, E.F., French, K.R., 1988. Permanent and temporary components of stock prices. Journal of Political Economy 96, 246-273.

Fama, E.F., French, K.R., 1993. Common risk factors in the returns on stocks and bonds. Journal of Financial Economics 33, 3-56.

Fama, E.F., French, K.R., 2015. A five-factor asset pricing model. Journal of Financial Economics $116,1-22$.

Fama, E.F., French, K.R., 2016. Dissecting anomalies with a five-factor model. Review of Financial Studies 29, 69-103.

Fama, E.F., French, K.R., 2017. International tests of a five-factor asset pricing model. Journal of Financial Economics 123, $441-463$.

Fama, E.F., French, K.R., 2018. Choosing factors. Journal of Financial Economics 128, $234-252$.

Fama, E.F., MacBeth, J.D., 1973. Risk, return, and equilibrium: Empirical tests. Journal of Political Economy 81, pp. 607-636.

Gibbons, M.R., Ross, S.A., Shanken, J., 1989. A test of the efficiency of a given portfolio. Econometrica: Journal of the Econometric Society, 1121-1152. 
Gompers, P.A., Metrick, A., 1998. Institutional Investors and Equity Prices. Working Paper 6723. National Bureau of Economic Research.

Granger, C.W.J., Ding, Z., 1995. Some properties of absolute return: An alternative measure of risk. Annales d'̋̋œconomie et de Statistique , 67-91.

Guo, B., Zhang, W., Zhang, Y., Zhang, H., 2017. The five-factor asset pricing model tests for the Chinese stockï¿œmarket. Pacific-Basin Finance Journal 43, 84- 106.

Gustafson, K.E., Miller, J.D., 1999. Where has the small-stock premium gone? The Journal of Investing 8, 45-53.

Hansen, B.E., 1992. Testing for parameter instability in linear models. Journal of Policy Modeling $14,517-533$.

Hansen, B.E., 2002. Tests for parameter instability in regressions with i(1) processes. Journal of Business \& Economic Statistics 20, 45-59.

Harvey, C.R., Liu, Y., Zhu, H., 2015. ... and the Cross-Section of Expected Returns. The Review of Financial Studies 29, 5-68.

Hou, K., Xue, C., Zhang, L., 2015. Digesting anomalies: An investment approach. Review of Financial Studies 28, 650-705.

Huang, T.L., 2018. Is the Fama and French five-factor model robust in the Chinese stock market? Asia Pacific Management Review .

Kozak, S., Nagel, S., Santosh, S., 2018. Interpreting factor models. The Journal of Finance 73, $1183-1223$.

Lettau, M., Ludvigson, S., 2001. Resurrecting the (C)CAPM: A Cross-Sectional Test When Risk Premia Are Time-Varying. Journal of Political Economy 109, 1238-1287.

Lintner, J., 1965a. Security prices, risk, and maximal gains from diversification. The Journal of Finance 20, 587-615.

Lintner, J., 1965b. The valuation of risk assets and the selection of risky investments in stock portfolios and capital budgets. The Review of Economics and Statistics, 13-37.

Lucas, R.E., 1978. Asset Prices in an Exchange Economy. Econometrica 46, 1429-1445.

Mandelbrot, B., 1963. The variation of certain speculative prices. The Journal of Business 36.

Morck, R., Yeung, B., Yu, W., 2000. The information content of stock markets: why do emerging markets have synchronous stock price movements? Journal of Financial Economics 58, 215 260. Special Issue on International Corporate Governance.

Newey, W.K., West, K.D., 1987. A simple, positive semi-definite, heteroskedasticity and autocorrelation consistent covariance matrix. Econometrica 55, 703-08.

Nyblom, J., 1989. Testing for the constancy of parameters over time. Journal of the American Statistical Association 84, 223-230.

Petersen, M.A., 2009. Estimating standard errors in finance panel data sets: Comparing approaches. The Review of Financial Studies 22, 435-480. 
Petkova, R., 2006. Do the Fama-French Factors Proxy for Innovations in Predictive Variables? The Journal of Finance 61, 581-612.

Pham, V.T.L., 2007. Constructing Fama-French Factors from style indexes: Japanese evidence. Economics Bulletin 7, 1-10.

Roll, R., 1988. R-squared. Journal of Finance 43, 541-566.

Sharpe, W.F., 1964. Capital asset prices: A theory of market equilibrium under conditions of risk. The Journal of Finance 19, 425-442.

Stock, J.H., Watson, M.W., 2007. Introduction To Econometrics. Boston: Pearson/Addison Wesley.

Wang, F., Xu, Y., 2004. What determines Chinese stock returns? Financial Analysts Journal 60, $65-77$.

White, H., 1980. A heteroskedasticity-consistent covariance matrix estimator and a direct test for heteroskedasticity. Econometrica 48, 817-838. 